Portland State University

PDXScholar

Fall 3-29-2016

\title{
A Relevance Rule Organizing Responsive Behavior During Projectably Multi-Unit Tellings
}

Anri Zama

Portland State University

Follow this and additional works at: https://pdxscholar.library.pdx.edu/open_access_etds

Part of the International and Intercultural Communication Commons, and the Interpersonal and Small Group Communication Commons

Let us know how access to this document benefits you.

\section{Recommended Citation}

Zama, Anri, "A Relevance Rule Organizing Responsive Behavior During Projectably Multi-Unit Tellings" (2016). Dissertations and Theses. Paper 2750.

https://doi.org/10.15760/etd.2751

This Thesis is brought to you for free and open access. It has been accepted for inclusion in Dissertations and Theses by an authorized administrator of PDXScholar. Please contact us if we can make this document more accessible: pdxscholar@pdx.edu. 
A Relevance Rule Organizing Responsive Behavior

During Projectably Multi-Unit Tellings

by

Anri Zama

A thesis submitted in partial fulfillment of the requirements for the degree of

Master of Science

in

Communication

Thesis Committee:

Jeffrey D. Robinson, Chair

Tanya Romaniuk

John Hellermann

Portland State University

2016 
(C) 2016 Anri Zama 


\begin{abstract}
Research on projectably multi-unit tellings (e.g., stories) has largely focused on their contexts of emergence, beginnings, endings, and uptakes (or lack thereof), rather than on their 'middles.' The relatively small literature on such 'middles' has focused on different types of responsive behaviors when they do occur (e.g., continuers). However, there is virtually no research on relevance rules that might systematically organize these 'middles,' including the production of responsive behaviors (or lack thereof) and the management of intersubjectivity. This thesis describes and defends one such relevance rule: Advisors are strongly accountable for responding - either vocally and/or nonvocally - at each and every complex possible-completion place. This relevance rule provides an inferential framework with which to monitor and manage advisors' understanding of 'middle' units. The method used is conversation analysis - including the analysis of deviant cases - complemented by the coding of data and resultant distributional patterns. Data are dual-camera-videotaped, drop-in, advising sessions conducted in English between 20 non-native-English-speaking international students and native-Englishspeaking advisors working for a university's Office of International Affairs. Specifically, data involve students' projectably multi-unit problem presentations (e.g., related to Visa status, course scheduling, international travel, housing, etc.).
\end{abstract}




\section{Dedication}

To my parents, husband, and daughter. 


\section{Acknowledgements}

I would like to express my deepest gratitude to my thesis advisor, Professor Jeffrey D. Robinson for his guidance, continuous support, patience, and immense wealth of knowledge. You made this thesis a reality. I am also grateful to Professors Tanya Romaniuk and John Hellermann for dedicating their time to read my thesis and for providing insightful comments.

I wish to thank all the participants: those great international student advisors at the Office of International Student and Scholar Services at PSU and the international students who made this research a possibility. Thank you for your time and willingness to participate.

Last but not least, I would like to thank my loved ones who have supported me: my family in Japan who patiently encouraged and supported me; my husband who believed in me, proofread, and challenged my ideas; my daughter who made me smile; and my dog, Momiji who often came out from the bedroom - when I stayed up late working on this thesis - to cuddle up on my lap. I will be forever grateful for your love. 


\section{Table of Contents}

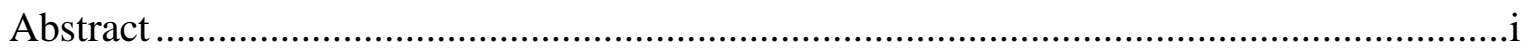

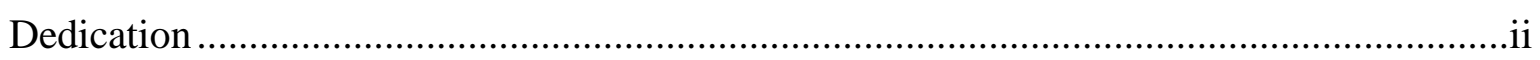

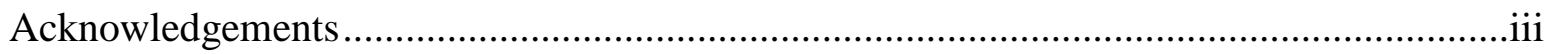

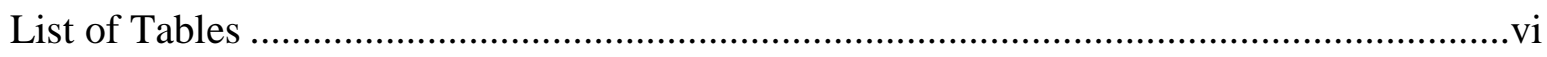

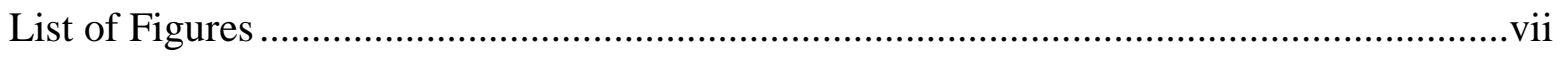

Chapter 1: Introduction and Literature Review ................................................................ 1

International Students Studying at Colleges and Universities in the United States ..2

Culture Shock and Adaptation ...............................................................................

Individualism and Collectivism ...........................................................................

Cross-Cultural Misunderstandings.......................................................................

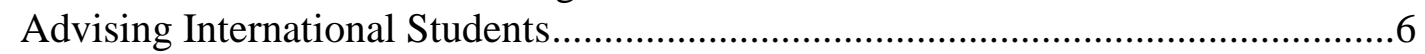

Projectably Extended Tellings and Understanding .................................................

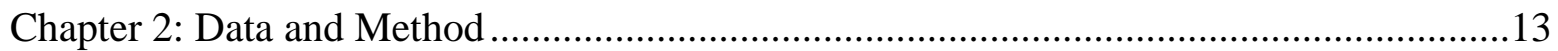

Data-Collection Site and Rationale......................................................................13

Qualitative Research: Conversation Analytic Approach ............................................14

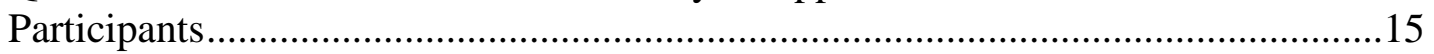

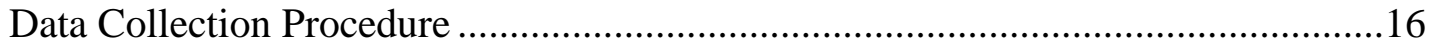

Room Layout and Participant Orientation ...............................................................17

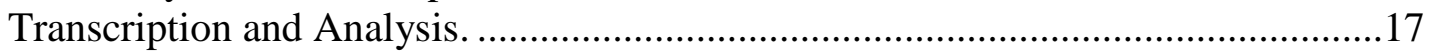

The Activity Context and Foci of Analysis ............................................................18

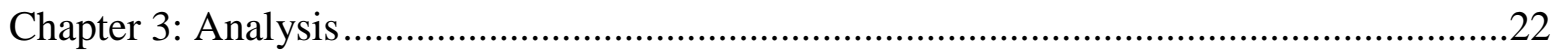

The Nature of a Possible-Completion Place ………………...................................22

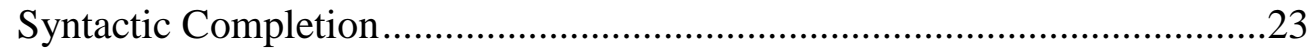

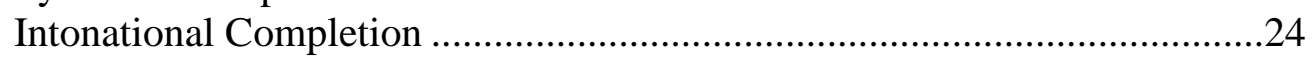

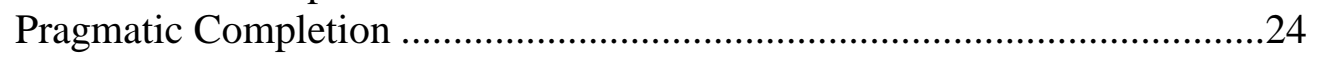

Specifying the Focal Engagement Framework ………….......................................26

The Frequency and Type of Advisors' Responses ...............................................2

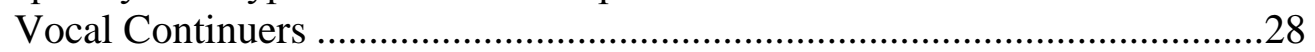

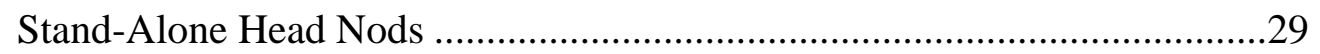

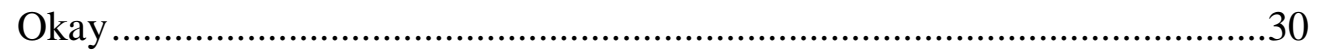

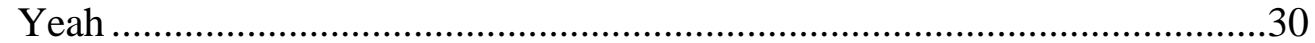

Positive Assessments ...............................................................................

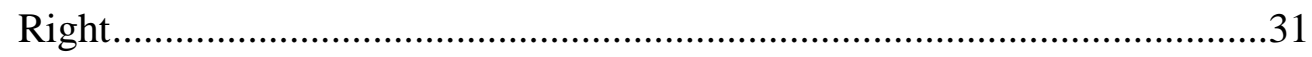

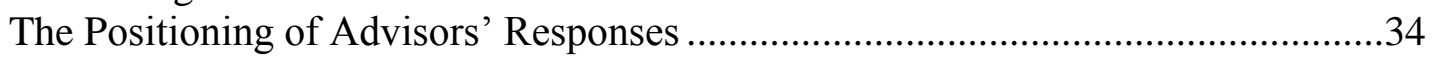

'Early' Responses ....................................................................................

'Precisely-On-Time' Responses ....................................................................36 


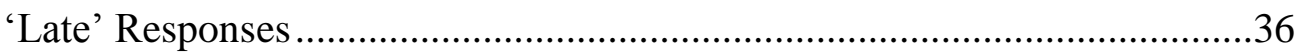

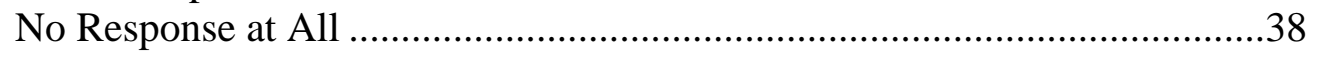

The Nature of Student Progression from Unit to Unit.............................................38

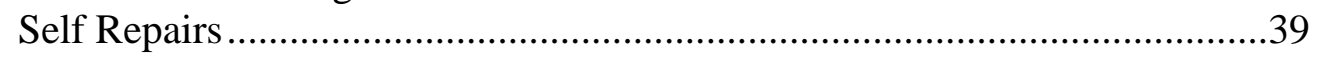

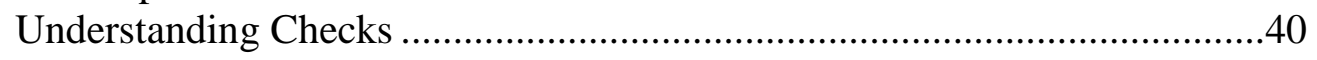

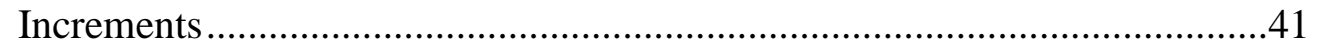

Answers to Advisors' Initiations of Repair ................................................44

The Relationship Between Position of Advisor Response and Student Progression..

Deviant-Case Analysis

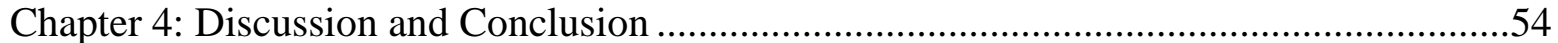

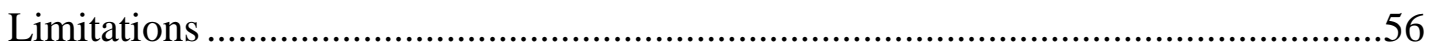

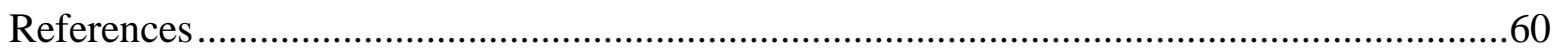

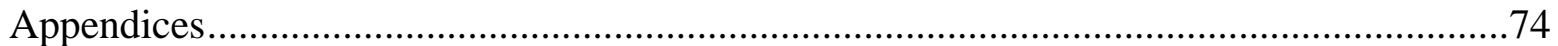

A: HSRRC Approval ................................................................................... 74

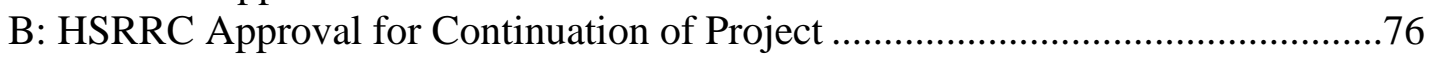

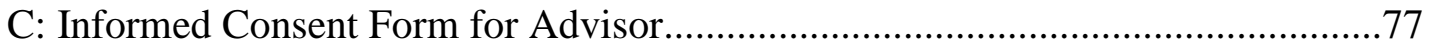

D: Informed Consent Form for International Student............................................... 79

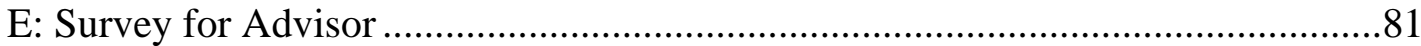

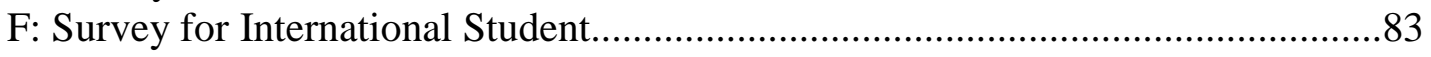




\section{List of Tables}

Table 1: Engagement Framework and Frequency ...................................................27

Table 2: Did Advisor Respond Around cPCP?........................................................27

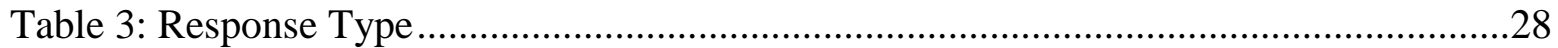

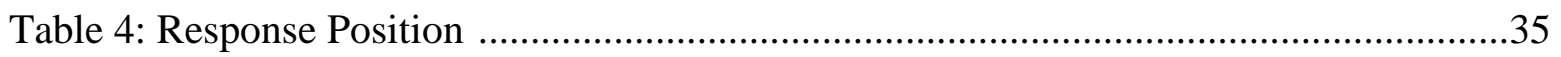

Table 5: Distribution of Cases Relative to Position of Advisor Response and Student

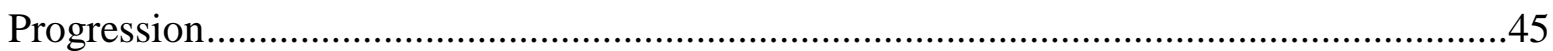




\section{List of Figures}

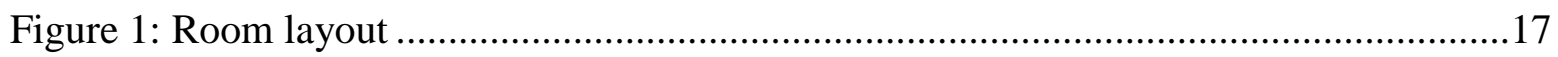

Figure 2a: Advisors oriented toward students with bodies and heads ............................27

Figure 2b: Advisors not oriented toward students with bodies and heads.........................27

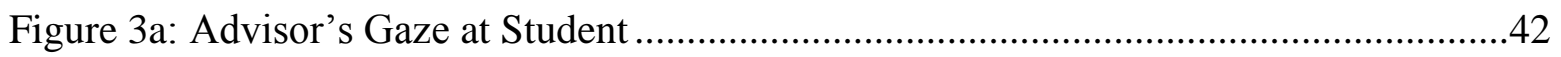

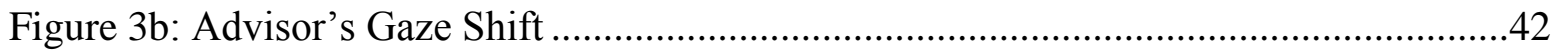

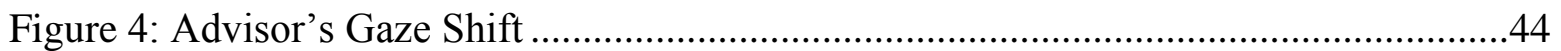

Figure 5a: Student gazing at the advisor .......................................................... 49

Figure 5b: Student gazing down and away to his left ................................................49 


\section{Chapter 1}

\section{Introduction and Literature Review}

Data for the present thesis are face-to-face advising sessions between universityemployed, native-English-speaking advisors and non-native, English speaking, international students. Specifically, data involve the 'problem-presentation' phase of such advising sessions, wherein advisors solicit problems/questions in an open-ended fashion (e.g., What can I do for you today?), and students provide problems/questions, all of which (in the present data) involve projectably extended tellings (i.e., ones that extend across multiple units of talk). The macro-analytic research questions that initially motivated the collection of these data were: (1) How are these advising sessions, and the institutional task of 'telling' problems/questions, hindered by 'understanding problems' or breakdowns in intersubjectivity, especially ones driven by intercultural and/or language differences?; and (2) How do participants manage to repair breakdowns in intersubjectivity? Accordingly, the following literature review establishes a basis for these research questions, including the importance of international-student advising sessions and the likelihood of entailing 'understanding problems.'

However, as is sometimes (and perhaps frequently) the case with inductive, qualitative research, the data ended up 'painting a different picture.' Specifically, after thorough analysis, the initial assumption that there would be 'understanding problems' (i.e., research question 1 , above) proved relatively groundless. What emerged was a novel finding that has much less to do with how participants repair breakdowns in intersubjectivity (i.e., research question 2, above) - although this topic is addressed in the present thesis - and has much more to do with the social-interactional resources (i.e., 
relevance rules) involved in participants maintaining intersubjectivity, per se. As such, the following literature review also deals with recipient-behavior during extended tellings and its relationship to the management of intersubjectivity.

The following literature review includes six subsections: (1) International students studying at colleges and universities in the United States; (2); Culture shock and adaptation; (3) Individualism and collectivism; (4) Cross-cultural misunderstandings; (5) Advising international students; and (6) Projectably extended tellings and understanding. International Students Studying at Colleges and Universities in the United States

U.S. colleges and universities have experienced an increase in internationalstudent enrollment. According to a report from Open Doors 2013, Institute of International Education, international-student enrollment during the 2012-2013 academic year increased by $7.2 \%$ from the previous year, with nearly 820,000 international students being enrolled at colleges and universities in the United States. These numbers are part of a steady, seven-year growth in international-student enrollment. There are $40 \%$ more international students studying at U.S. colleges and universities than there were ten years ago. Not only do international students bring diversity and cross-cultural understanding to campuses and host communities, they also contribute to them financially. The Open Doors 2013 reports indicates that international-student spending contributed approximately $\$ 24$ billion to the U.S. economy in the 2012-2013 academic year.

Fluency in English, length of study period, and purpose of study vary from one international student to another; however, international students face common issues and stressors, such as culture shock and stressors associated with academic and immigration 
requirements involving the maintenance of student-visa status in order to live and study in the U.S. For example, during the school year, twelve credits per term are required for undergraduate-international students and nine credits per term are required for graduateinternational students. International students may be authorized to reduce their course load with adequate reasons, such as preparing for comprehensive examinations or working on graduate theses. The increasing number of international students at colleges and universities in the U.S. has prompted the need for additional, special services, including immigration counseling, academic advising, and day-to-day life support to help with students' cultural and social adjustment.

\section{Culture Shock and Adaptation}

Translocation across country and culture is sometimes accompanied by stressful and intense emotional experiences referred to as 'culture shock.' Negative effects of culture shock include at least loneliness, anxiety, and fear (Ting-Toomey \& Chung, 2005); however, culture shock can also involve positive experiences. At least in my own experience, being forced to see one's self in different and positive ways can be very rewarding. Culture shock tends to follow a 'W-shaped' adjustment model involving five 'stages' (ibid.): (1) excitement about translocating to a new environment and meeting new people; (2) homesickness due to cultural differences/difficulties; (3) acclimation to the new cultural environment and host culture; (4) when faced with returning to their home countries, international students often experience mixed feelings; and (5) after returning to their home cultures international students may experience culture shock again (i.e., reverse culture shock in struggling with identities associated with their host and home cultures.) The affect and duration of culture shock vary from one international 
student to another. Some students experience all of the aforementioned stages, while others may experience only one or two stages and for varying durations.

Maintaining positive expectations and developing positive social relationships help international students adjust to new environments and thus manage culture shock in healthy ways. Ting-Toomey \& Chung (2005) argued that there exists a pattern whereby friendship networks are forged with other international students of similar cultural backgrounds and/or with people from other cultures through recreational activities. Because international students typically face difficulties - in terms of adjusting to the host country (U.S.), as well as academic and social settings - it is important to have access to organizations and services that support them to adjust to their new environments. As a result, quality services for international students are in high demand because of today's increasing number of international students in U.S. universities (Hammons et al., 2004; Hayes \& Lin, 1994; Perrucci \& Hu, 1995).

\section{Individualism and Collectivism}

Intercultural researchers have long divided societies into two roughly different types: individualistic and collective (Hall \& Hall, 2002; Ting-Toomey \& Chung, 2005). Individualistic societies - such as American, Australian, British, French, German, Scandinavian, and Swiss - value "individual achievements, failures, and rights over the collective" (Beamer \& Varner, 2005, p. 115). On the other hand, collective societies such as East-Asian, Southeast-Asian, Mediterranean, Latino, Middle-Eastern, and African - value "the group above the individual, and individuals have a responsibility to the group that supersedes individual needs or rights" (ibid., p. 115). The individualistic/collective distinction is not dichotomous, but rather a matter of degree. 
Members of individualistic and collective cultures tend to adopt different communication styles, referred to as 'low context' and 'high context,' respectively (Hall \& Hall, 2002; Ting-Toomey \& Chung, 2005). A low-context communication style which is frequently adopted by people from, for example, America, Canada, Germany, and Sweden - involves being direct, animated, and informal, with a preference for talkativeness. A high-context communication style - which is frequently adopted by people from, for example, Japan, South Korea, Kuwait, and Mexico - involves being indirect, understated, and formal, with a preference for silence. In the present study, the majority of the international students were from East-Asian collectivist cultures, while the advisors were from the US, an individualistic society.

\section{Cross-Cultural Misunderstandings}

It is normal that people from different cultures experience conflicts due to cultural differences, at least due to different understandings of normative or appropriate behaviors (Gudykunst, 1998). That is, communication is influenced by speakers' personal cultural norms, these norms often vary by culture, and speakers are often not fully aware of either their own, or others' cultural norms. Thus, intercultural conflict tends to emerge from intercultural misunderstandings (Ting-Toomey, 1999). According to Ting-Toomey, in order to manage and avoid intercultural conflict, interactants need to be able to understand each other's cultural differences, listen carefully to each other, translate each other's verbal and non-verbal messages from one cultural to another, and build trust with each other. Additionally, interactants must be flexible and adaptable. 


\section{Advising International Students}

As mentioned above, because of an increasing number of international students in

the U.S., there is an increasing demand that they be provided with high-quality university services (Hammons et al., 2004; Hayes \& Lin, 1994). The role of international-student advisor involves at least the goal of keeping international students in school and in the U.S. legally, and thus involves at least the provision of immigration counseling, academic advising, and day-to-day support both related and unrelated to students' immigration status. While studying abroad, international-student advisors provide some of the most helpful resources to international students.

It has been established that university-student advising for international students is a context in which they receive needed support, something that is potentially hindered by advisor-student misunderstanding. It is important to approach international students with cultural sensitivity because, relative to American students, international students face additional problems and concerns (Cadieux \& Wehrly, 1986), such as those with language, finances, and adjusting to new educational, social, and cultural systems (Lee, Abd-Ella, \& Burks, 1981). For example, Cadieux and Wehrly (1986) noted that nonWestern international students may orient to the disclosure of problems to non-family members (e.g., as they do in international-student advising sessions) as being shameful. Therefore, when international students do seek advising, it is important to facilitate and encourage their efforts.

Arguably, one critical part of the advising process - and thus one in which 'misunderstanding' is especially detrimental - occurs at the opening phase of meetings where advisors solicit students' problems/questions and student 'tell' about them, 
including providing background information believed to be necessary for properly addressing their problems/questions. While there are studies examining native speaker and non-native speakers of English in academic advising sessions (e.g., Bardovi-Harlig \& Hartford, 1993), there have been virtually no prior studies on this specific phase of this institutional context (for one possible exception, see Kidwell, 2000). However, an analogous phase that has received much attention has been that of patients 'presenting problems' to physicians (Heath, 1981; Heritage \& Robinson, 2006a, 2006b; Maynard \& Heritage, 2005; Robinson, 1998, 2006; Robinson \& Heritage, 2005, 2006). According to Ruusuvuori (2001), “[o]nly the problem or problems introduced at the beginning of the consultation are regularly taken into consideration by doctor and those presented later ... are more easily ignored" (p. 1093). In studies of doctor-patient interaction, patient's problem presentation segment is one of the most important phases (Maynard \& Heritage, 2005; Robinson \& Heritage, 2005; Ruusuvuori, 2001) because doctors can fail to assemble dependable information from patients when doctors do not adequately listen to their patients. Complete problem presentations -ones in which patients are able to present their complete agenda of concerns and in which patients perceive that their presentations are listened to - are associated with increased patient satisfaction (Robinson \& Heritage, 2005).

\section{Projectably Extended Tellings and Understanding}

Conversation analysis (hereafter CA) has a storied history studying stories or, more generally, projectably multi-unit tellings (e.g., Goodwin, 1981, 1984, 1986a; Halkowski, 2006; Heritage \& Robinson, 2006a; Jefferson, 1978; Kasper \& Prior, 2015; Mandelbaum, 1987, 1989, 1993, 2003, 2010; 2013; Robinson \& Heritage, 2005; Sacks, 
1974; Sacks , Schegloff, \& Jefferson, 1974; Stivers, 2008). The bulk of this research has focused on the beginnings and endings of such tellings, with an interest in how the suspension of turn-by-turn talk (Sacks, Schegloff, \& Jefferson, 1974) is achieved and resumed, the actions that tellings accomplish, and how tellings as courses of action sequentially organize subsequent action.

Within this work, the 'middles' of projectably multi-unit tellings have been relatively epiphenomenal. However, one of the earliest contributions of CA which stood in stark contradistinction to previous conceptualizations of storytelling (e.g., Labov, 1972; Labov \& Waletzky, 1967), empirically demonstrated that and how "the 'audience' is in fact the co-author ... with recipient turns playing a crucial role in shaping and even constituting the ongoing course of the storytelling" (Mandelbaum, 2013, p. 501; emphasis original; see also Duranti, 1986; Goodwin, 1986a, 1986b). In the same vein, Iwasaki (2009) further examined projective and multimodal structures inside a turn-constructional unit (TCU) where co-participants provide for collaborative participation.

Overall, there has been a gamut of research on the type, positioning, function, and consequences of recipients' responses (or, as labeled early on, 'back-channel' behavior; Yngve, 1970) including minimal response tokens (e.g., Clancy, Thompson, Suzuki, \& Tao, 1996; Drummond \& Hopper, 1993; Gardner, 2001; Guthrie, 1997; Jefferson, 1984; Schegloff, 1982) as well as disruptive responses (M. H. Goodwin, 1997; Mandelbaum, 2010). Schegloff (1982) argued that response tokens (e.g., Uh huh, Mm hm, Okay, etc.) claim (but do not display) understanding insofar as they formally pass on an opportunity to initiate repair. Gardner (2001) claimed that "response tokens provide information to other participants in the talk not only about how some prior talk has been receipted, but 
also some information on how the response token utterer is projecting further activities in the talk" (p. 3). Oreström (1983) claimed that listeners' responses show their understanding to the current speaker. Lambartz (2011) argued that listeners' use of responses such as "yeah" and "mm" demonstrate engaged listenership. These types of response tokens have been studied across different languages (e.g., Clancy, Thompson, Suzuki, \& Tao, 1996; Maynard, 1990, 1997).

Nodding frequently accompanies vocal response tokens such as "yeah" and "mmhmm” (Dittmann \& Llewellyn, 1968) and plays an important role in giving visual feedback (Allen \& Guy, 1974; Saiga, Sumi, \& Nishida, 2011), specifically in terms of recipients' affiliative stances (Stivers, 2008). By nodding, "the hearer displays support and endorses the teller's conveyed stance" (ibid., p. 35). Generally, there exists a good deal of research done on the consequences of non-vocal responses to include "visual orientation, gesture, and other forms of bodily comportment" (Heath \& Luff, 2013, p.283; emphasis original see Atkinson, 1984; C. Goodwin, 1979, 1981; M. H. Goodwin, 1980; Heath, 1982, 1986; Schegloff, 1984).

What is missing from this research is a description of the relevance rules, if any, that guide responsive behavior during the middles of projectably multi-unit tellings and how these rules might reflexively influence tellers' construction of middle units. While we know that rules regarding turn transition are suspended during such middles - that is, rules regarding the completion of tellings as courses of action and the transition from tellers' to next speakers' full-fledged turns - we know very little about rules that might inform transitions from one middle unit to the next. Although we appear to know a lot about minimal response tokens when they do occur, we know relatively little about when 
they do not occur, precisely because of our limited understanding of governing relevance rules.

CA's central preoccupation with action formation and ascription fundamentally relies on identifying, describing, and explicating relevance rules of both practices and actions (e.g., Atkinson \& Heritage, 1984; Levinson 2013; Robinson 2007; Schegloff 1996a, 2007; Sidnell, 2010, 2013). Relevance rules involve both normative structures of reasoning and normative patterns of conduct (Robinson 2007; Schegloff, 2007). For example, we normally construct turns with specific units (Sacks, Schegloff, \& Jefferson, 1974) and current speakers are normally initially entitled to single units of talk (ibid.). Relevance rules not only have 'implications' for interlocutors' understandings of 'what just happened,' as well as of 'what just did not happen,' but also for interlocutors' immediately subsequent conduct. Schegloff and Sacks (1973) referred to these latter 'implications' in terms of 'sequential implicativeness.' One subset or type of relevance rule involves conditional relevance (Schegloff, 2007), which involves a 'close-order' sequential implicativeness (Schegloff \& Sacks, 1973). For example, the first-pair part of an adjacency-pair sequence makes a second-pair part conditionally relevant (Schegloff, 2007) such that the omission of a second-pair part is accountably 'officially absent' (Schegloff, 1968).

Even a brief examination of the middles of projectably extended tellings shows that they are 'messy' in at least the following ways. Although tellers hold the rights to the floor to grossly progress (Sacks, Schegloff, \& Jefferson, 1974) toward projected endpoints, middles are filled with apparently unprompted and/or unnecessary pausing, repetition, backtracking, clarification, etc. And although recipients can and do sometimes 
respond, and do so in an organized manner (e.g., at possible-completion places; Sacks, Schegloff, and Jefferson, 1974; Schegloff, 2007), there are many instances where recipients do not respond, either vocally or non-vocally at possible-completion places. Sometimes, participants orient to this lack of a response, other times not. One is left with a nagging suspicion that - somehow, someway, in some contexts - there might be a relationship between recipients' lack of response and tellers' pausing, repetition, backtracking, clarification, etc., but nothing systematic has yet emerged. A relevance rule regarding responsive behavior is exactly the sort of mediating phenomenon that could begin to organize - indeed, explain - such messiness.

Of course, the presence, absence, and nature of relevance rules guiding responsive behavior during projectably extended tellings almost assuredly vary according to their nature as courses of action (e.g., a joke, vs. a story, vs. a problem presentation), their contexts (e.g., ordinary vs. institutional), and the type of participation framework adopted by their participants (e.g., telling while unengaged in other activities and co-oriented with body and gaze vs. telling while cooking or showering). If so, naturalistically studying such rules in a rigorous fashion requires not only controlling for at least these parameters, but examining a relatively large corpus of like tellings (Atkinson \& Heritage, 1984). As such, the present thesis attempts to document such a rule, and its consequences, during one particular institutional activity. Admittedly, from a basic CA standpoint, this research would optimally be conducted on ordinary conversation (e.g., Heritage, 2004; Peräkylä, 1997; Schegloff, 1987a). However, collecting enough data while controlling for the requisite parameters makes doing so currently infeasible, and is a long-term goal for future research. The present thesis attempts to document such a relevance rule in the 
present data as a proof of concept. 


\section{Chapter 2}

\section{Data and Method}

\section{Data-Collection Site and Rationale}

This study was approved by PSU's Human Subjects Research Review Committee (see Appendix A \& B). This thesis sought interaction data that: (1) were naturally occurring; (2) involved embodied co-presence; (3) included one native-English speaker and one non-native-English speaker; and (4) represented a speech activity (Guthrie, 1997; Levinson, 1979) in which the non-native-English speaker normatively occupied the majority of the 'conversational floor.' As such, this thesis targeted the 'problem presentation' phase of advising sessions between native-English-speaking university advisors and non-native-English speaking international students. About these types of advising sessions, Guthrie (1997) said:

These sessions are an example of what Heritage \& Greatbatch (1989) refer to as "quasi-conversational" institutional talk-in-interaction, that is, talk-in-interaction that is institutional insofar as (a) one of the participants is a representative of an institution and the other is a layperson, (b) the activities in which the participants are engaged are task-and role-based, and (c) the participants' orientation to the institutionality of the interaction is evidenced through the ongoing talk. However, despite the institutionality of the setting, the turn-taking and sequential structures are more like those found in ordinary conversation, as opposed to those found in institutional setting such as a courtroom, a public hearing, or a press conference (He 1993:8). (p. 397) 
Data were collected at the Office of International Affairs (OIA), Room 101, East Hall at Portland State University (PSU). The OIA oversees all of the major international activities at PSU and has, as a major function, the provision of support to international students. A major component of this support is student-life and immigration advising for more than 2,000 international students from over 100 countries.

Appointments were conducted in English. None of the appointments were prescheduled, being held during drop-in hours, which were dedicated to a particular institutional activity (Levinson, 1979; Robinson, 2013), that being students seeking advice or knowledge toward the solution of some practical problem regarding, for example, academic issues (e.g., course scheduling, degree completion, enrollment, program admission, etc.; 8 appointments), immigration (4 appointments), optional practical training (4 appointments), job eligibility ( 2 appointments), and travel restrictions (2 appointments).

\section{Qualitative Research: Conversation Analytic Approach}

Conversation analysis (CA) is a naturalistic, qualitative method that allows researchers to study the "social organization of human interaction" (Roberts \& Robinson, 2004, p. 376). CA emerged in the late 1960s and is related to ethnomethodology. Ethnomethodology was developed by the sociologist Harold Garfinkel (1967). Harvey Sacks developed conversation analysis with his associates Emanuel Schegloff and Gail Jefferson. CA focuses on "small-scale social order seen through the common social knowledge of members of society of the forces that influence how individuals interpret the situations and messages they encounter in their social world" (Liddicoat, 2007, p. 2). CA offers "a rigorous methodology of data collection and analysis that is uniquely suited 
to addressing the problems and exploiting the opportunities posed by human interaction as an object of inquiry" (Clayman \& Gill, 2004, p. 589). CA examines "patterns and principles of interaction, particularly in the area of turn-taking and the sequential organization of talk" (Ford \& Thompson, 1996, p. 134).

As Atkinson and Heritage (1984) noted about CA:

$[\mathrm{I}] \mathrm{t}$ represents a departure both from the use of interviewing techniques in which the verbal reports of interview subjects are treated as acceptable surrogates for the observation of actual behavior and from the use of experimental methodologies in which the social scientist must necessarily manipulate, direct, or otherwise intervene in the subjects' behavior. (p. 2)

CA proceeds from the collection of audio/video data, to its transcription, to its analysis (for review, see Sidnell, 2009). Research shows that transcribed audio/video data is both reliable and valid (Clayman \& Gill, 2004; Roberts \& Robinson, 2004).

\section{Participants}

Participants included three native-English-speaking advisors from the division of International Student and Scholar Services within the Office of International Affairs who regularly deal with issues relating to students' F-1 VISA status, such as course scheduling, degree completion, international travel, immigration, and housing. Participants also included 20 adult (over 18 years old) international students (at PSU) who were nonnative English speakers who visited (drop-in hours from 1:00 to 4:00 PM) the Office of International Affairs to consult with advisors regarding some 'problem' or 'question.' Based on 18/20 student responses to a post-session questionnaire (two students declined to answer), students were of predominantly (89\%) Asian descent who were an average of 
26.7 years old (Range=20-33; $\mathrm{SD}=3.6$ ) and who had been speaking English (in either their native country or the US) for an average of 12.4 years (Range=1-25; $\mathrm{SD}=6.6$ ). Drop-in hours were targeted because they represent the largest portion of student visits. The study's 20 advising visits represented a convenience sample (MacNealy, 1999).

Participants were informed that the study concerned the nature, and potential improvement, of communication between native and non-native English speakers, and that their visits would be videotaped. Prior to visits, participants were given, and signed informed-consent forms (see Appendices C \& D), and the researcher answered any remaining questions about the study. Immediately before visits, participants completed a short paper-and-pencil questionnaire (see Appendices E \& F).

\section{Data Collection Procedure}

Data were collected during the Spring quarter of 2010. Prior to collecting any video data, the researcher approached advisors, explained the research, and solicited their informed consent. If advisors agreed to participate, they were allowed to read, and then signed, the informed consent form. After this, advisors completed a short questionnaire asking about basic demographic information (See Appendix E). The researcher arrived at the Office of International Affairs at 12:30 PM (30 minutes prior to the beginning of drop-in hours) and prepared for data collection. In order to capture non-vocal behavior accurately (e.g., nodding, body orientation, gaze, etc.), it was necessary to include two camera angles, one facing each participant. Thus, two video cameras mounted on tripods were positioned in visit rooms (see Figure 1: Room layout, below).

After international students checked in at the front desk, the researcher approached them, explained the research, and solicited their informed consent. If students 
agreed to participate, they were allowed to read, and then signed, the informed consent form. After this, students completed a short questionnaire asking them about basic demographic information, as well as about their English fluency (See Appendix F). As students completed the questionnaires, the researcher turned on the video cameras. Video cameras were running as students entered advisors' offices, and the researcher was not present during advising sessions. At the completion of each day's drop-in hours (around 4:00 PM), the researcher removed all video equipment.

\section{Room Layout and Participant Orientation}

Appointments were conducted in one of three rooms, all of which provided for a similar engagement framework (Goodwin, 1981) in which advisors and students faced one another (sometimes with an intervening desk) and advisors had a computer to their left (see Figure 1).

Figure 1: Room layout

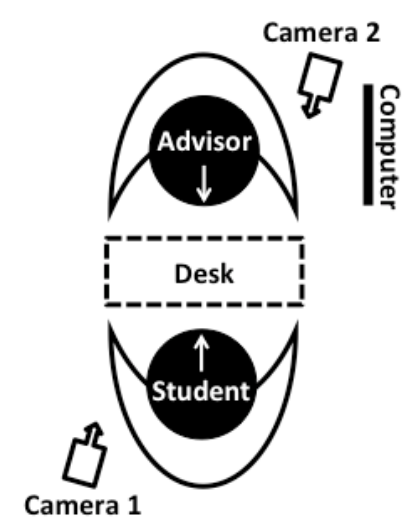

\section{Transcription and Analysis}

Data were transcribed for both vocal and non-vocal behavior, especially nodding and gaze orientation (Goodwin, 1981; Hepburn \& Bolden, 2013; Jefferson, 2004; See Sidnel, 2009 for transcript conversion). In addition to vocal and verbal transcription, that 
of nodding took approximately 90 hours. The primary method used is conversation analysis (for review, see Atkinson \& Heritage, 1984; Clayman \& Gill, 2004), particularly as it is applied to the study of institutional interaction (Drew \& Heritage, 1992). CA also informed the coding of data (Stivers, 2015), which provided additional, distributional support for claims (Robinson, 2007).

\section{The Activity Context and Foci of Analysis}

This article focuses on students' problem-presentations, and specifically on their 'middles.' For an example of the phenomenon, see Extract 1 (which does not include the transcription of advisors' nodding):

Extract 1: [\#3-\#29]

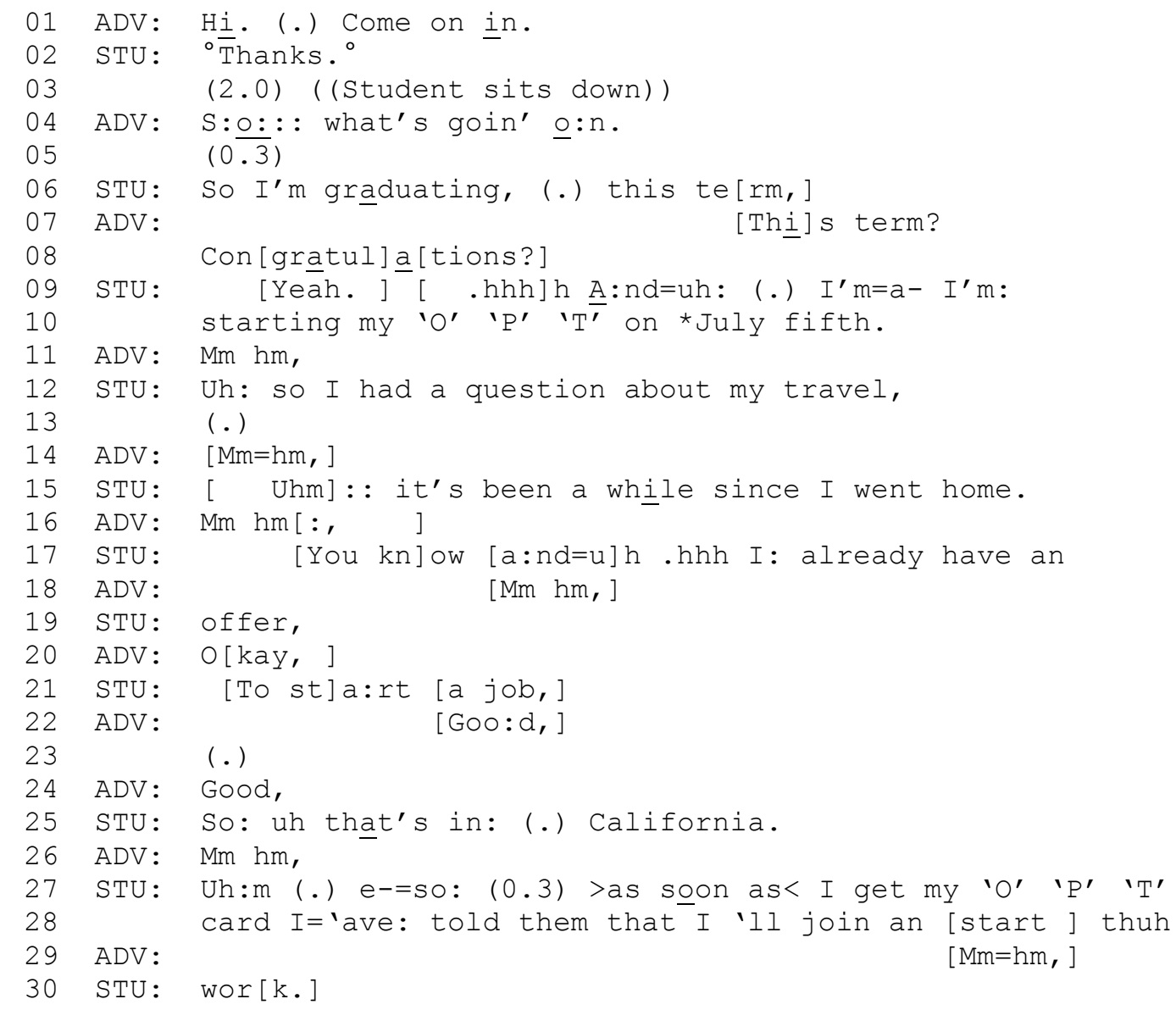




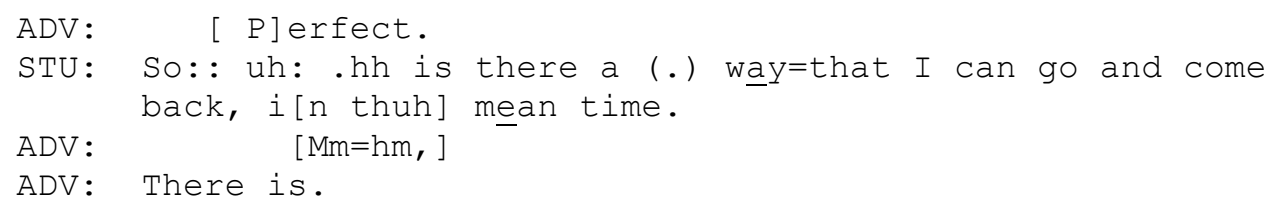

In all 20 appointments, after advisors and students opened interactions (Schegloff, 1986) - which involved both advisors and students greeting one another and sitting and organizing themselves in preparation for business (Extract 1, above, lines 1-3; Robinson, 1998) - advisors solicited students' business in an open-ended fashion: "S:ㅁ::: what's

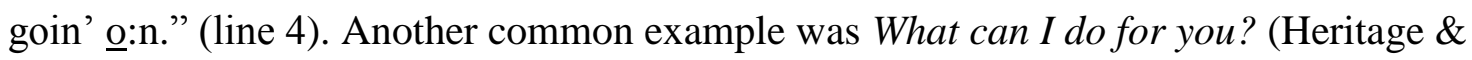
Robinson, 2006b; Robinson, 2003). In no appointments did students' initial turnconstructional units constitute their conditionally relevant 'answers,' that is, their focal problem/question. Rather, students always began a 'problem-presentation telling' (Halkowski, 2006; Mandelbaum, 2013; Robinson, 1998, 2006) by variously presenting or establishing background information designed to facilitate advisors' understandings of students' focal problem/question (Goodwin, 1984; Mandelbaum, 2013; Sacks, 1974). Thus, students' initial answer units were preliminary (Schegloff, 2007) to their focal business.

For example, in Extract 1, the student does not present his focal business until lines 32-33. The student's multi-unit answer contains eight turn-constructional units (to be defined more extensively later). The student's final/eighth unit constitutes the presentation of his focal business, and thus possibly completes his presentation of business: "So:: uh: .hh is there a (.) way=that I can go and *come back, i[n thuh] mean time." (lines 32-33). The student's initial seven TCUs (at lines 6, 9-10, 12, 15, 17-21, 25, and 27-30, respectively) are projectably preliminary to his focal business, and do not 
possibly complete his presentation of business. For example, the student initially answers by announcing good news (Extract 1): "So I'm graduating (.) this te[rm,]" (line 6). Insofar as this announcement is not one of an OIA-related 'problem,' it is projectable as being preliminary to a conditionally relevant answer to the advisor's question. Similarly, the student's second TCU/action, "I'm=a- I'm: starting my 'O' 'P' 'T' on *July fifth." (lines 9-10; O.P.T. stands for Optional Practical Training), does not constitute an OIArelated 'problem.' The student's third TCU/action (line 12), "Uh: so I had a question about m*y travel," projects a question (Schegloff, 2007), but does not constitute his business (lines 32-33). The students' fourth through seventh TCUs (at lines 15, 17-21, 25, and 27-30, respectively) involve the provision of background knowledge necessary for being able to adequately answer his focal question. In sum, after the advisor's question at line 4, the student has the right to the conversational floor (Heritage \& Robinson 2006b) until the completion of his focal business/question at lines 32-33.

In every appointment, students' 'answers' were packaged in terms of projectably multi-unit turns. That is, because advisors' solicitations (e.g., What's going on?) made conditionally relevant presentations of 'actionable problems,' and because students' initial turn-constructional units never constituted such problems, students' initial turnconstructional units were projectable (Lerner, 1996; Liddicoat, 2004; Robinson, 2006) as not 'answering' advisors' solicitations, and thus as not possibly completing the sequence (or course of action; Schegloff, 2007). All such preliminary, non-complete actions (e.g., in Extract 1, above, at lines 6, 9-10, 12, etc.) were considered to be 'middle' units of students' presentations. Even though it was technically relevant for advisors to 'enter' students' turn spaces (Sacks, Schegloff, \& Jefferson, 1974) at the possible completion of 
'middle' units - for example with continuers, including nodding (Goodwin, 1986b;

Jefferson, 1984; Schegloff, 1982; Stivers, 2008) - such entry was 'conditional' (Lerner, 1996) due to the fact that students still held the right to the floor to complete their tellings.

In Extract 1, the student's presentation is possibly complete after they answer with their projected question at lines 32-33: "So:: uh: .hh is there a (.) way=that I can go and come back, in thuh mean time." 


\section{Chapter 3}

\section{Analysis}

The forthcoming analysis section leads up to, and ultimately supports, the claim that advisors and students organize themselves, during presentation 'middles,' according to the relevance rule that advisors respond at every possible-completion place of every unit in the 'middle' of students' presentations. It is argued that, akin to conditional relevance (Schegloff 1968, 1972; Schegloff \& Sacks, 1973), this rule makes advisors strongly accountable for responding, such that a non-response is socially visible and generative of sense-restorative inferences (Heritage, 1984). The analysis has seven subsections involving: (1) the nature of a 'possible-completion place'; (2) specifying the focal participation framework; (3) the frequency and type of advisors' responses; (4) the positioning of advisors' responses; (5) the nature of student progression from unit to unit; (6) the relationship between position of advisor response and student progression; and (7) deviant-case analyses.

\section{The Nature of a Possible-Completion Place}

Sacks, Schegloff, and Jefferson (1974) described the rules for turn taking for ordinary conversation and proposed that turns are comprised of a basic unit of talk referred to as a 'turn constructional unit' (hereafter TCU). Sacks et al. identified some unit types as follows:

Unit-types for English include sentential, clausal, phrasal, and lexical constructions. Instances of the unit-types so usable allow a projection of the unittype under way, and what, roughly, it will take for an instance of that unit-type to be completed. (Sacks et al. 1974, p. 702) 
The end of a TCU is a point of possible completion and is referred to as a 'possible completion place.' It is also a place where speaker change may occur. Even in the context of extended tellings (e.g., stories), where current speakers have rights to the floor until their tellings are complete, participants nonetheless produce and understand talk with an orientation to possible-completion places.

Possible-completion places are constructed and recognized according to rules involving syntax, intonation, and pragmatics (Ford \& Thompson, 1996), which are orthogonal concepts. For instance, it is possible for a unit to be syntactically complete, but neither intonationally nor pragmatically complete, or for a unit to be intonationally complete, but neither syntactically nor pragmatically complete, and so on.

Syntactic completion. Following Ford and Thompson (1996), this thesis considered "preceding context to the extent that it is responsible for the recoverability of reference" (p. 144), and "judged an utterance to be syntactically complete if, in its discourse context, it could be interpreted as a complete clause, that is, with an overt or directly recoverable predicate, without considering intonation or interactional import," including "elliptical clauses, answers to questions, and backchannel responses" (p. 143). For several examples of possible syntactic completion, in Extract 1 (above), the student's turn at line 6 comes to two places of possible syntactic completion, initially after "So I'm graduating", and then again after "this term". In the student's turn at lines 9-10, the student's turn comes to two places of possible syntactic completion, initially after “I'm=a- I'm: starting my 'O' 'P' 'T'”, and then again after “on *July fifth". The student's turn at line 12 comes to two places of possible syntactic completion, initially after "Uh: so I had a question", and then again after "about my travel,". The student's turn at line 15 
comes to two places of possible syntactic completion, initially after "Uhm:: it's been a while", then after "since I went home.".

Intonational completion. Again following Ford and Thompson (1996), this thesis used Dubois et al.'s (1993) definition of intonational possible completion as the completion of "a stretch of speech uttered under a single coherent intonation contour" (cited in Ford \& Thompson, 1996, p. 145), with unit-final-rising and unit-final-falling intonation being the two most common contours signaling finality. In the present transcription system, unit-final-rising intonation is symbolized by a comma (for a slight rise) and a question mark (for a strong rise), and unit-final-falling intonation is symbolized by a period. For several examples of possible intonational completion, in Extract 1 (above), at lines 9-10, while the student's turn comes to two places of possible syntactic completion (i.e., after "I'm=a- I'm: starting my 'O' 'P' ' $T$ '”, and “on *July fifth."), it only comes to possible intonational completion once after "on July fifth.", which ends with falling intonation (as indicated by a period). At line 12, while the student's turn has two places of possible syntactic completions (after "Uh so I had a question" and "about $\mathrm{m}^{*} \mathrm{y}$ travel,"), a possible intonational completion point comes only once after "about $\mathrm{m}^{*} \mathrm{y}$ travel," with a slight rising intonation. At line 15, while the student's turn comes to two possible syntactic completions (after "Uhm:: it's been a while" and "since I went home."), it only comes to possible intonational completion after "since I went home.", which ends with falling intonation.

Pragmatic completion. According to Ford and Thompson (1996), possible pragmatic completion "is conceived of based on the potential that any utterance has for constituting an action in an interactional sequence" (p. 148). Ford and Thompson 
distinguish between two types of pragmatic completion: local and global. The present thesis is primarily concerned with local places, or "points at which the speaker is projecting more talk, but at which another speaker might reasonably take a minimal turn, such as offering a continuer, display of interest, or claim of understanding" (p. 150). For several examples of possible pragmatic completion, in Extract 1 (above), the student's turn at lines 9-10 comes to two places of possible pragmatic completion, initially after "A:nd=uh: (.) I'm=a- I'm: starting my 'O' 'P' 'T'”, and then again after "on *July fifth.”. These places also coincide with places of possible syntactic completion, and the latter place (“*July fifth.”) also coincides with a place of possible intonational completion. At line 12, the student's turn comes to two places of possible pragmatic completion, initially after "Uh: so I had a question" and then "about m*y travel,". Both of these places coincide with places of possible syntactic completion, and the latter place ("about $\mathrm{m}^{*} \mathrm{y}$ travel,") also coincides with a place of possible intonational completion. At line 15, the student's turn only comes to one place of possible pragmatic completion, after "it's been a while since I went *home.”, which coincides with places of possible syntactic and intonational completion. This unit is arguably not pragmatically possibly complete after "while" insofar as the indexical term "it's" does not yet have an anchoring reference (nor is it intonationally complete after "while").

As discussed above, while there are at least three different aspects of possible completion (e.g., syntactic, intonational, and pragmatic; see above), and while each of these can be accountably 'exploited' by potential next speakers (Sacks, Schegloff, \& Jefferson, 1974), this thesis focused on complex possible-completion places (hereafter abbreviated as cPCPs), or places where units simultaneously came to possible syntactic, 
intonational, and pragmatic completion. Although Ford and Thompson (1996) refer to these places as complex transition-relevance places (i.e., cTRPs), this thesis refers to them as cPCPs because, upon possible completion of middle units of projectably extended tellings, it is not technically relevant to transition from one full-fledged turn to another (see Schegloff, 1982). That is, students continue to hold rights to their telling turns, even though advisors have occasional rights of what Lerner (1996) called conditional entry. Therefore, this thesis coded for cPCPs because they are ones where next-speaker entry into the turn, even if 'conditional' (Lerner, 1996), is relevant.

For example, in Extract 1 (above), the student's units at lines 9-10, 12, and 15 only come to one $\mathrm{cPCP}$, that is, after the completion of " $\mathrm{I}$ ' $\mathrm{m}=\mathrm{a}$ - I'm: starting my ' $\mathrm{O}$ ' 'P' 'T' on *July fifth.", "so I had a question about $\mathrm{m} * \mathrm{y}$ travel," and "it's been a while since I went *home.", respectively. Note that, while these units have other types of places of possible completion (e.g., merely syntactic, etc.), the cPCPs are the only places where the advisor orients to possible completion (at lines 11, 14, and 16, respectively). Across all 20 presentations, there were 185 cPCPs of 'middle' units (with each presentation having an average of 7.9 middle units; Mode=5; Range=2-35).

\section{Specifying the Focal Engagement Framework}

Of the 185 cPCPs of 'middle' units, this thesis only deals with $163(88 \%)$ that occurred in a particular engagement framework (Goodwin, 1981), where advisors were oriented toward students with both their bodies and heads, as represented in Figure 2a (below) (Table 1, below). In this engagement framework, advisors embodied a claim of complete and 'uncontaminated' engagement with students. This article does not deal with the minority $12 \%$ of cases $(\mathrm{N}=22)$ where advisors were oriented toward (and often using) 
computers, as represented in Figure $2 \mathrm{~b}$ (below) as this 'torqued' engagement framework (Robinson, 1998; Schegloff, 1998a) fundamentally alters norms of participation for both advisors and students, at least due to advisors embodied claim to be currently and/or primarily engaged with computer work.

Figure 2a: Advisor oriented toward student

Figure 2b: Advisor not oriented toward student
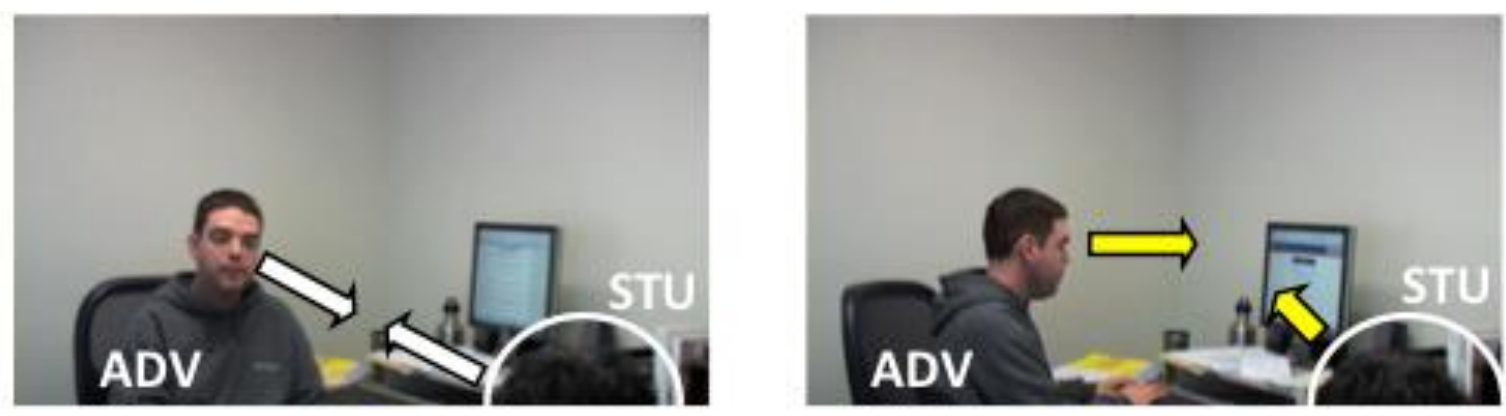

Table 1: Engagement Framework and Frequency

\begin{tabular}{lr}
\hline Engagement Framework & \multicolumn{2}{c}{ Frequency } \\
Yes (Advisor's body towards student) & $163(88 \%)$ \\
No (Advisor's body towards computer) & $22(12 \%)$ \\
\hline Total & $185(100 \%)$ \\
\hline
\end{tabular}

\section{The Frequency and Type of Advisors' Responses}

The relevance rule being proposed is initially supported distributionally: A

binomial probability test (tabulated below in Table 2) shows that advisors are significantly more likely to respond in some way at (or around) the cPCP of the 163 focal 'middle' units $(147 / 163 ; 90 \%)$ than not $(16 / 163 ; 10 \% ; \mathrm{p}<.001)$.

Table 2: Did Advisor Respond Around cPCP?

\begin{tabular}{lr}
\hline Did Advisor Respond Around cPCP? & Frequency \\
\cline { 2 - 2 } Yes & $147(90 \%)$ \\
No & $16(10 \%)$ \\
\hline Total & $163(100 \%)$ \\
\hline
\end{tabular}


Table 3: Response Type

\begin{tabular}{lrr}
\hline Response Type & \multicolumn{2}{c}{ Frequency } \\
\cline { 2 - 2 } Vocal Continuer (e.g., Mm hm, Uh huh) & $82(56 \%)$ \\
Stand-Alone Head Nod & 33 & $(22 \%)$ \\
Okay & 19 & $(13 \%)$ \\
Right & 1 & $(1 \%)$ \\
Yeah & 6 & $(4 \%)$ \\
Assessment (e.g., Good) & 3 & $(2 \%)$ \\
Other-Initiated Repair & 3 & $(2 \%)$ \\
\hline Total & $147(100 \%)$ \\
\hline
\end{tabular}

98\% of these 147 embodied responses (see Table 3 above) were what Gardner (2001) termed minimal responses, including:

Vocal continuers. The most frequent type of minimal response token (see Table 3) was the vocal continuers (Schegloff, 1982) Mm hm and $U h$ huh (82/147; 56\%). For an example of 'Mm hm' see Extract 2.

Extract 2: [\#2-\#22]

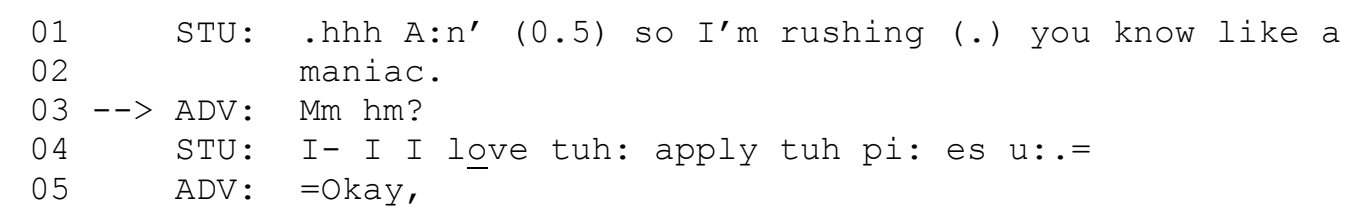

The student comes to a cPCP after "...maniac.” (line 2). After a normal transition space, the advisor responds with the continuer, "Mm hm?" (line 3). Note that, upon completion of the advisor's continuer, the student progresses his telling toward his focal business with another TCU: "I- I I love tuh: apply tuh pi: es u:.” (line 4).

For an example of 'Uh huh,' see Extract 3.

Extract 3: [\#3-\#31]

01 ADV: Hhhh what can I do for ya. 


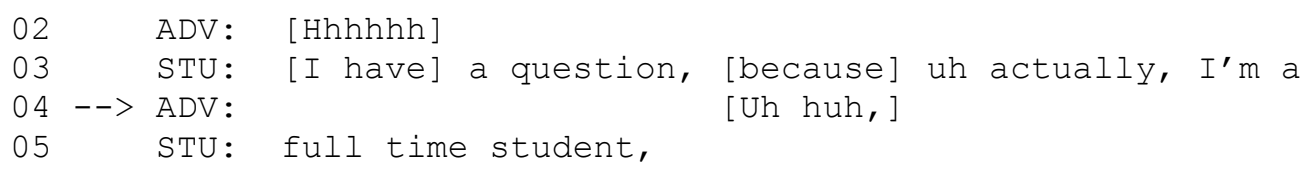

After the advisor solicits the student's business in line 1, the student states that she has a question, which comes to a cPCP after "a question," (line 3 ). The advisor responds with the continuer "Uh huh,". In overlap with the advisor's continuer, the student progresses her telling toward her focal business with another TCU: "because uh actually, I'm a full time student,".

Stand-alone head nods. The second most common type of minimal response token was a stand-alone head nod $(33 / 147 ; 33 \%)$. For example, see Extract 4 . Note that photographic stills are not presented because they do not clearly demonstrate nodding. The advisor begins to nod immediately upon possible completion of the student's unit after "full." (line 19b).

Extract 4: [\#1-\#21]

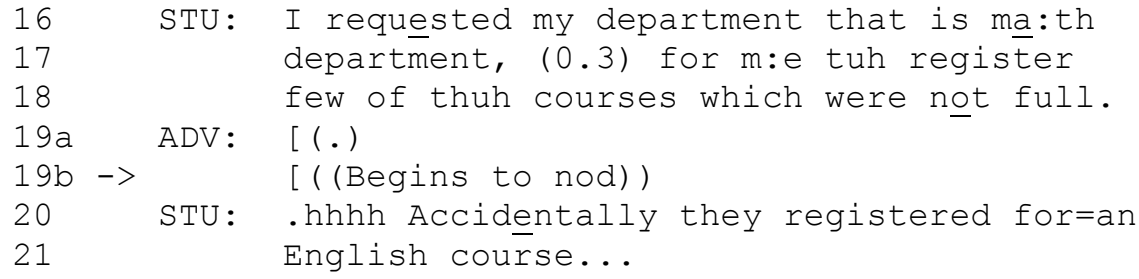

As we discuss below, the fact that the student subsequently progresses his telling (lines 20-21; re. progression, see Lerner, 1996) is some evidence that the student orients to the stand-alone head nod as a normal or unmarked minimal acknowledgement token. This position is strengthened by the fact that stand-alone head nods accounted for a third of all advisors' responses. 
For another example of a stand-alone head nod, see Extract 5. The advisor begins to nod immediately upon possible completion of the student's unit after "fi:ne." (line 3).

Extract 5: [\#2-\#22]

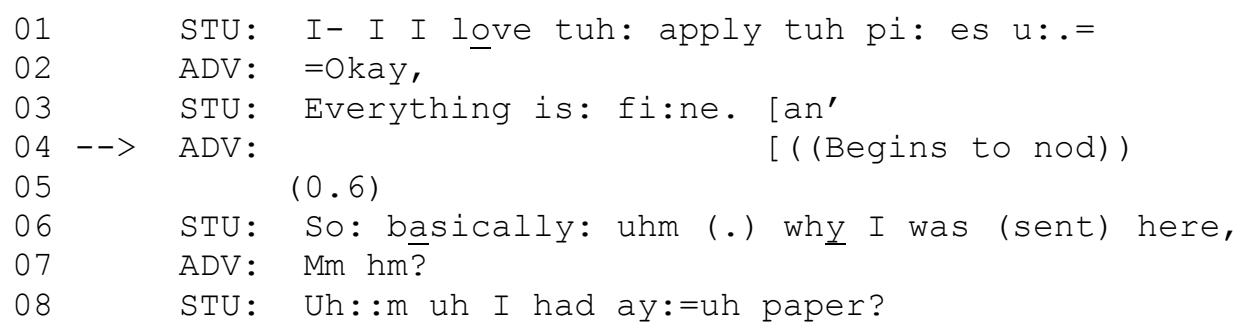

After the advisor's nod, the student progresses his telling by projecting his focal business: "So: basically: uhm (.) why I was (sent) here," (line 6).

Okay. The third most common type of minimal response was the word Okay $(19 / 147 ; 13 \%)$. In the context of students' projectably incomplete responses, advisors' Okays functioned as continuers. For example, see Extract 6.

Extract 6: [\#1-\#14]

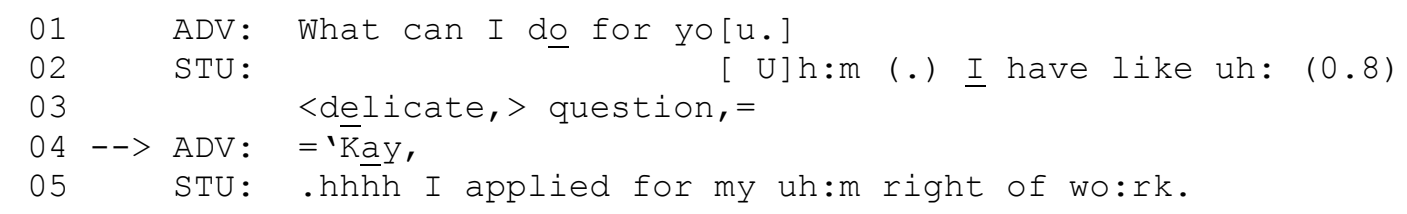

After the advisor solicits the student's business (line 1), the student states that she has a delicate question, which comes to a cPCP after "...< delicate, $>$ question,” (line 3 ). The advisor responds with "“Kay,”, after which the student progresses her telling by presenting novel background information (line 5).

Yeah. The fourth most common type of minimal response was the word Yeah, Yes, or Yep (6/147; 04\%). Again, in the context of students' projectably incomplete responses, variants of Yeah functioned as continuers. For example, see Extract 7. 
Extract 7: [\#1-\#14]

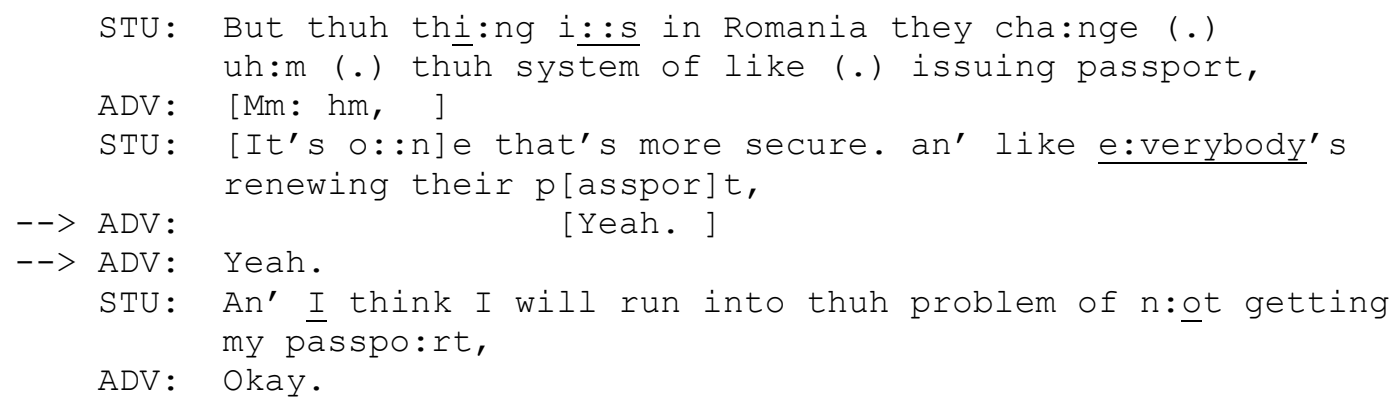

At lines 19-23, the student explains that her home country, Romania, has changed procedures regarding the issuance of passports. The student comes to a cPCP after “...renewing their passport," (lines 22-23). The advisor responds with the agreement token "Yeah." Both prior to possible completion (line 24), and again in the normal transition space (line 25). The student continues by progressing her telling: “An’ I think I will run into thuh problem of n:ot getting my passpo:rt," (lines 26-27).

Positive assessments. The fifth most common type of minimal response was a positive assessment (3/147; 02\%). For example, see Extract 8 . At lines 17-21, the student tells good news about having secured a job offer: "I: already have an offer, ... To sta:rt a job,".

Extract 8: [\#1-\#21]

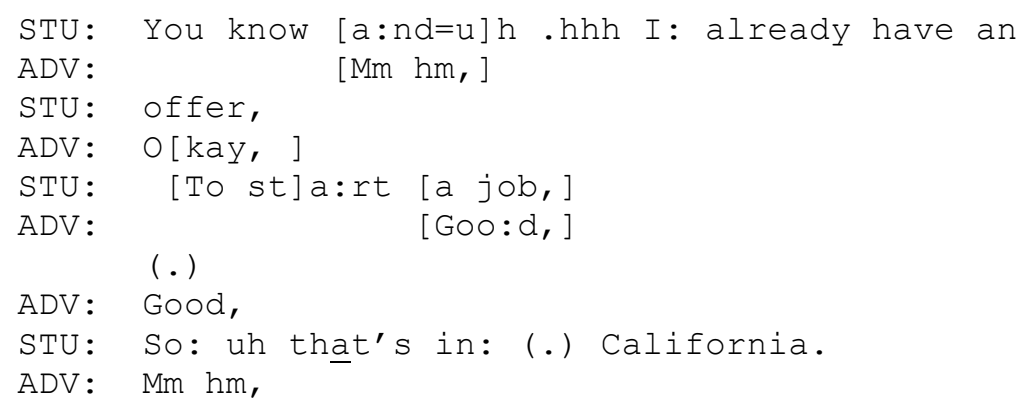


The student comes to a cPCP after “...job,” (line 21). At lines 22 and 24, the adviser responds with variants of Good, after which the student progresses his telling: "So: uh that's in: (.) California." (line 25).

Right. The sixth and least-frequent type of minimal response was the word Right $(1 / 147 ; 01 \%)$. For example, see Extract 9 , line 8.

Extract 9: [\#3-\#16]

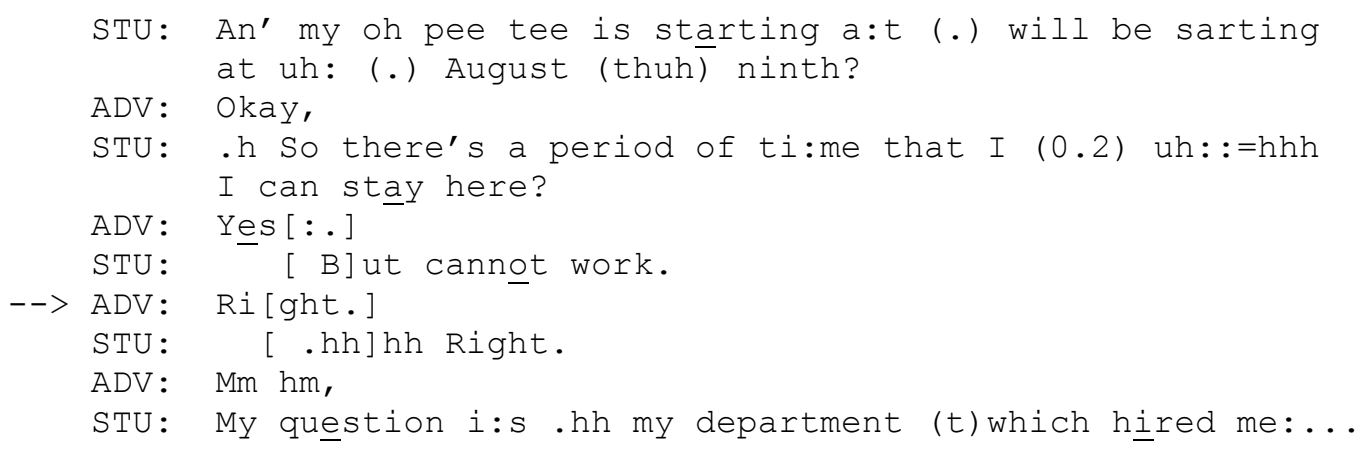

The remaining responses were not minimal, but rather other-initiations of repair (3/147; 02\%). For example, see Extract 10.

Extract 10: [\#3-\#29]

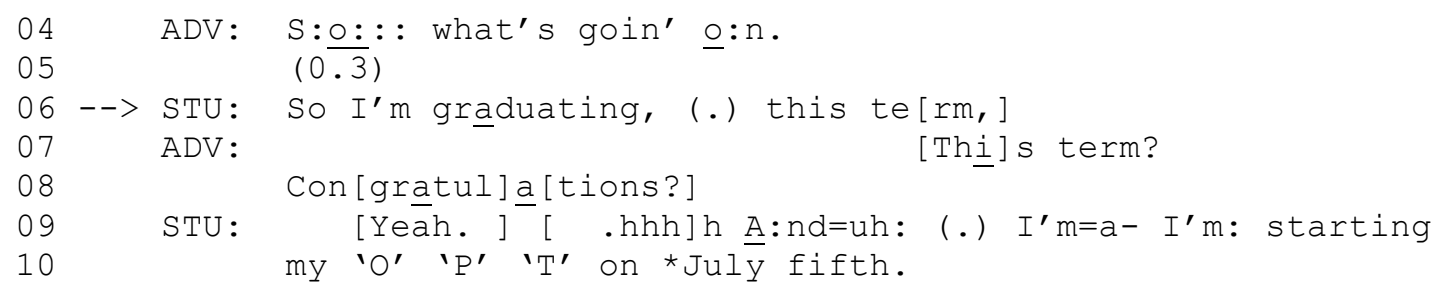

The student comes to a cPCP after: "So I'm graduating," (line 6). The advisor responds 'late' and initiates repair (see below for an analysis of response position). Specifically, the advisor produces a syntactic increment (Ford, Fox, \& Thompson, 2002) to the student's prior unit, “This term?" (line 7), and produces it with interrogative (or 
final-rising) intonation (symbolized in the transcript by the question mark), to clarify the timeframe of graduation.

For another example, see Extract 11.

Extract 11: [\#2-\#35]

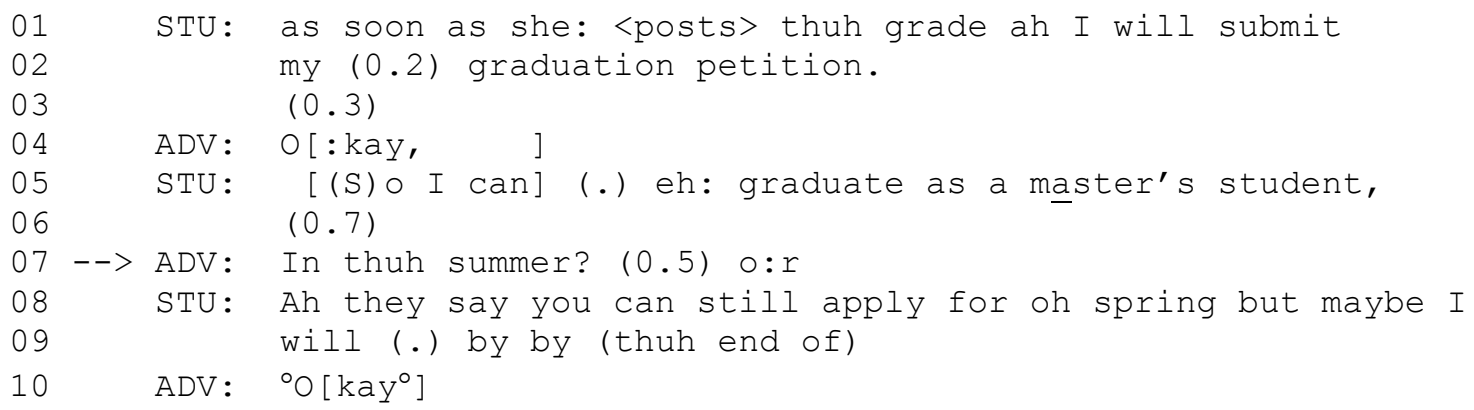

The student comes to a cPCP after: “(S)o I can (.) eh: graduate as a master's student," (line 5). As in Extract 10 (above), the advisor responds 'late' and initiates repair. Again similar to Extract 10 (above), the advisor produces a syntactic increment (Ford, Fox, \& Thompson, 2002) to the student's prior unit, "In thuh summer?” (line 7), and produces it with interrogative (or final-rising) intonation (symbolized in the transcript by the question mark), to clarify the timeframe of graduation.

For the third example, see Extract 12.

Extract 12: [\#3-\#31]

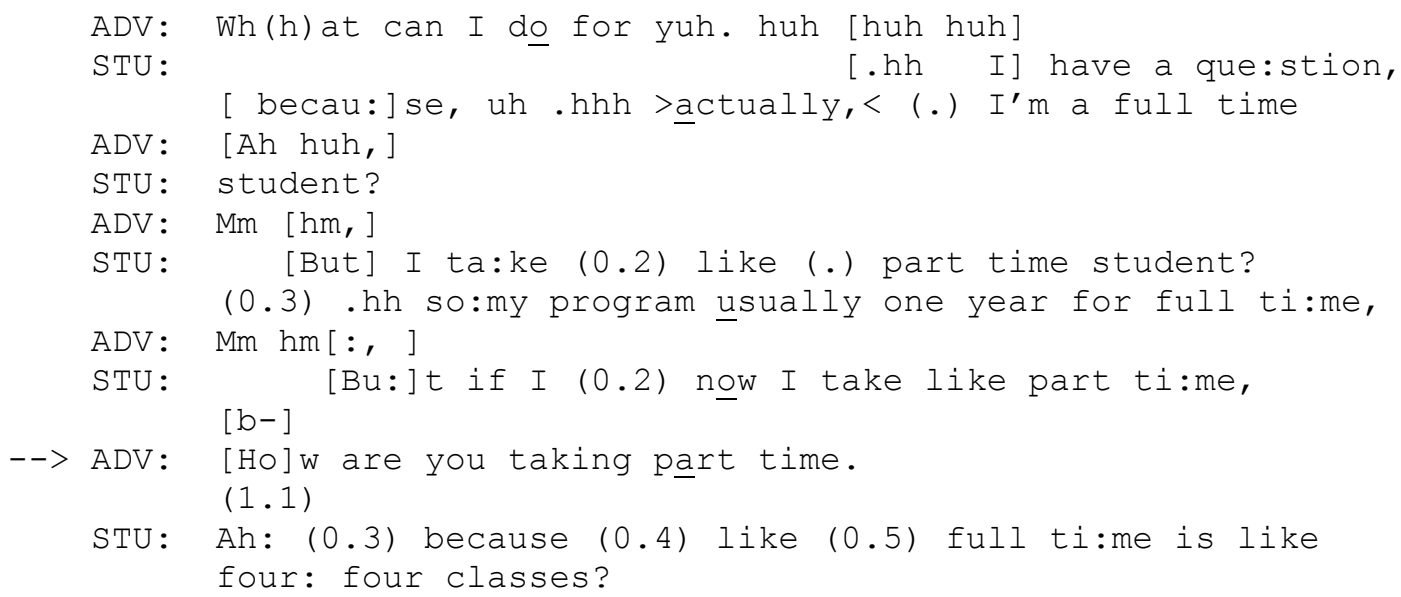


The student comes to a cPCP after, "now I take like part ti:me," (line 10), where she seems to be indicating that she is currently a part-time student. The student's assertion is 'troublesome' for two reasons. First, it directly contradicts the student's prior assertion of: "I'm a full time student?" (lines 3-5). Second, due to the student's international status, she is required to be a full-time student. The advisor responds by seeking clarification: "How are you taking part time." (line 12).

While nodding never co-occurred with other-initiation of repair, it frequently cooccurred with most other minimal responses, including with: (1) vocal continuers (77/82; 93.9\%); (2) Okay (18/19; 94.7\%); (3) Yeah (6/6; 100\%); and (4) Right (1/1; 100\%).

Nodding only co-occurred with $1 / 3(33.3 \%)$ of assessments. For an example of cooccurrence, see Extract 13 (below, which is a partial reproduction of Extract 1, above). At a place where the student is not yet possibly complete, but rather 'recognizably' complete (i.e., after 'I'm=a- I'm: starting my 'O' 'P' 'T' on..."; lines 9-10; Sacks, Schegloff, \& Jefferson, 1974), the advisor begins to nod (line 11a). Immediately upon possible completion of the student's unit after "fifth." (line 10), the advisor responds with "Mm hm," (line 11b) while nodding.

Extract 13: [\#3-\#29]

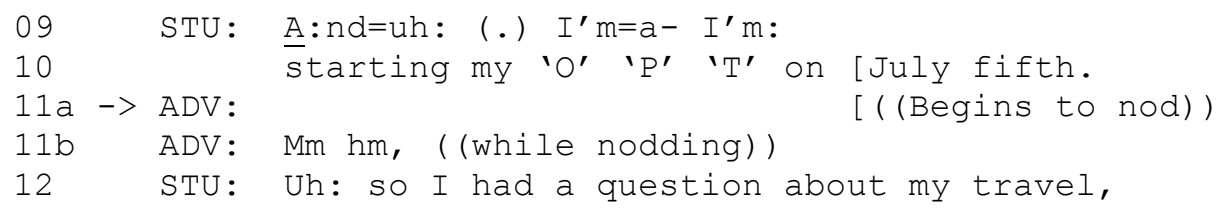

In sum, the magnitude of the statistical likelihood that advisors produce some type of response at (or around) cPCPs (see distribution above) suggests that responses are not 
simply relevant, but that they are accountably relevant; That advisors are not merely able to enter the turn space in a conditional manner (Lerner, 1996), but that they labor under an obligation to do so.

\section{The Positioning of Advisors' Responses}

In order to bolster support for, and to explicate, the proposed relevance rule, I examined where advisors' responses were positioned relative to cPCPs. In cases where nodding co-occurred with vocal minimal responses, I considered the beginning of the nod to constitute the beginning of the response (Schegloff, 1984). As might be expected given the rules for turn taking (Sacks, Schegloff, \& Jefferson, 1974), 79\% of responses (129/163) were positioned either just before the cPCP (i.e., 'early') or immediately after it within an unmarked transition space (i.e., 'on time'; Jefferson, 1986). 11\% of responses $(18 / 163)$ came late, that is, after an unmarked transition space. In $10 \%$ of the cases (16/163), there was no response at all, vocal or non-vocal. These results are summarized in Table 4.

Table 4: Response Position

\begin{tabular}{lr}
\hline Response Position & Frequency \\
Early or precisely at cPCP & $129(79 \%)$ \\
Late (i.e., after cPCP) & $18(11 \%)$ \\
No response at all & $16(10 \%)$ \\
\hline Total & $163(100 \%)$ \\
\hline
\end{tabular}

'Early' responses. For an example of an 'early' response, see Extract 14. The student's unit, "Uhm:: it's been a while since I went home." (line 15) comes to a cPCP after "home.", yet the advisor begins to nod (line 16) after "went".

Extract 14: [\#3-\#29]

12 STU: Uh: so I had a question about my travel, 


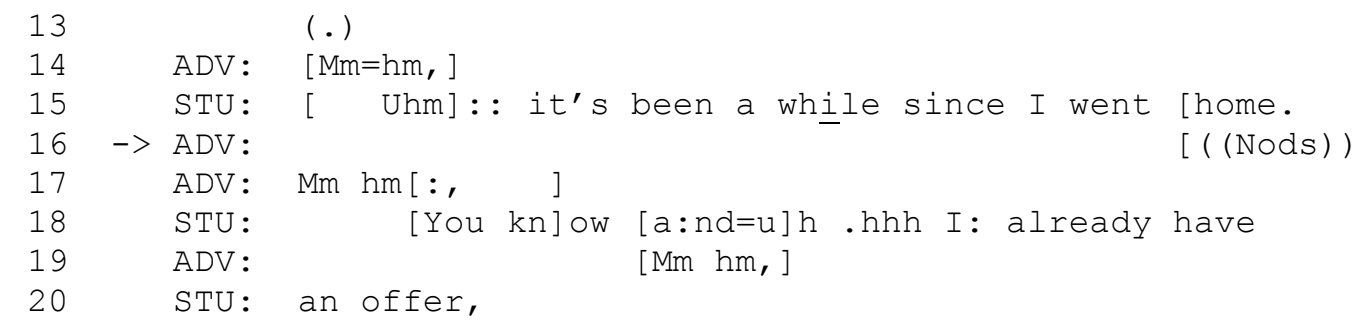

For another example, see Extract 15. The student's unit, “an’ like e:verybody’s renewing their passport," (lines 21-23), comes to a cPCP after "passport," (line 23), yet the advisor begins to respond after "renewing th..." (line 23).

Extract 15: [\#1-\#14]

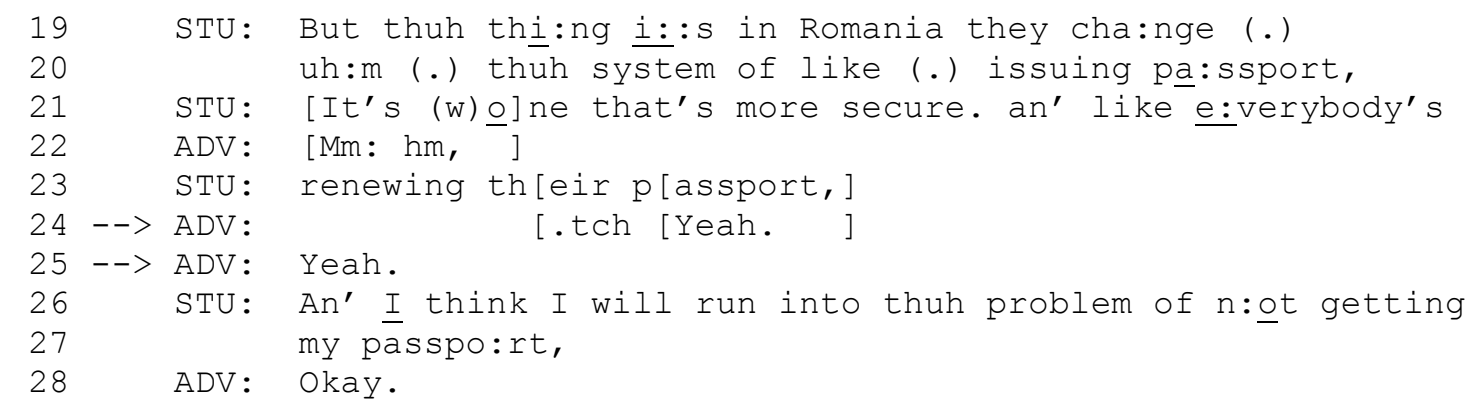

In the transition space after "passport," (line 23), the advisor recycles (Schegloff, 1987b) her agreement token: "Yeah.” (line 25).

'Precisely-on-time' responses. For an example of a response that is 'precisely on time', see Extract 16. The student comes to a cPCP after “...tuh pi: es u:?” (line 4). The advisor nods and produces "Mm hm?" (line 5) in the trailing, unmarked transition space.

Extract 16: [\#2-\#22]

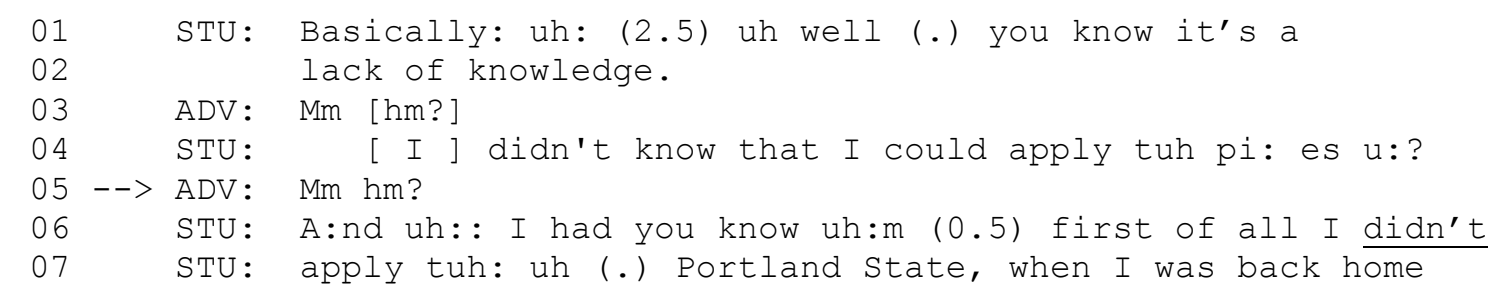


For another example, see Extract 17. The student's unit, "You know a:nd=uh .hhh I: already have an offer," (lines 18-20) comes to a cPCP after "offer," (line 20), and immediately thereafter the advisor simultaneously produces "Okay," (line 21a) and nods (line 21b).

Extract 17: [\#3-\#29]

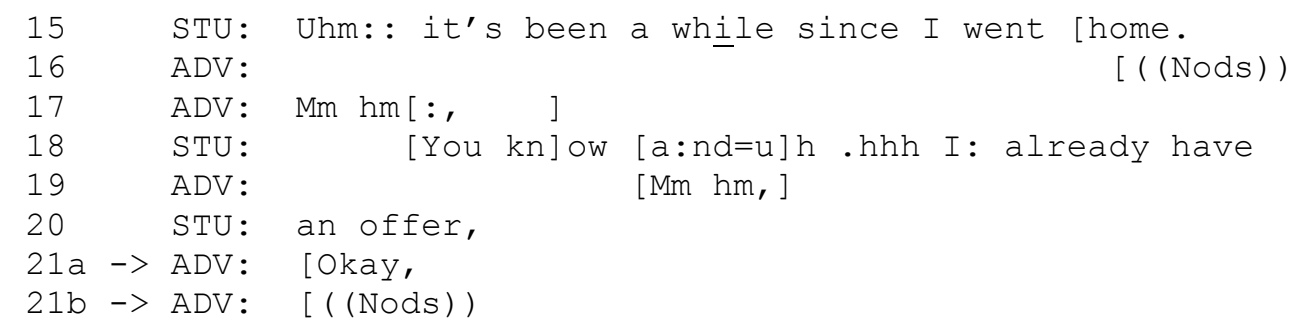

'Late' responses. Responses that came after unmarked transition spaces (Jefferson, 1986) were considered to be 'late.' For example, see Extract 18. The student's unit at lines 3-5, “Uh:m (2.4) li:ke (.) a week ago:? (.) I got (.) (0.2) thuh:: thuh receipt?”, comes to a cPCP after "receipt?" (line 5). After two-tenths of a second (line 6) - that is, late - the advisor simultaneously produces “.mtch Okay.” (line 7a) and nods (line 7b).

Extract 18: [\#1-\#6]

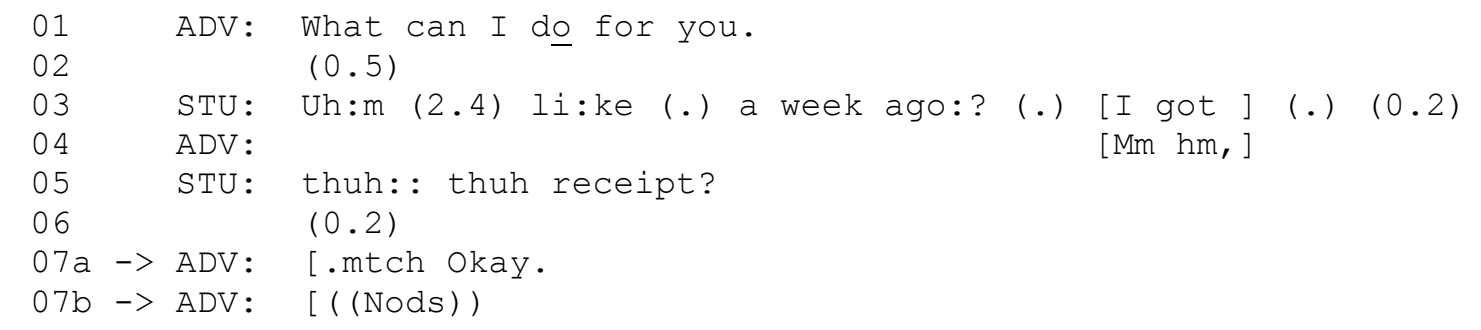

For another example, see Extract 19. The student comes to a cPCP after: "(S)o I can (.) eh: graduate as a master's student," (line 5). There ensues a 0.7-second silence at line 6 before the advisor responds by initiating repair: "In thuh summer?" (line 7).

Extract 19: [\#2-\#35] 


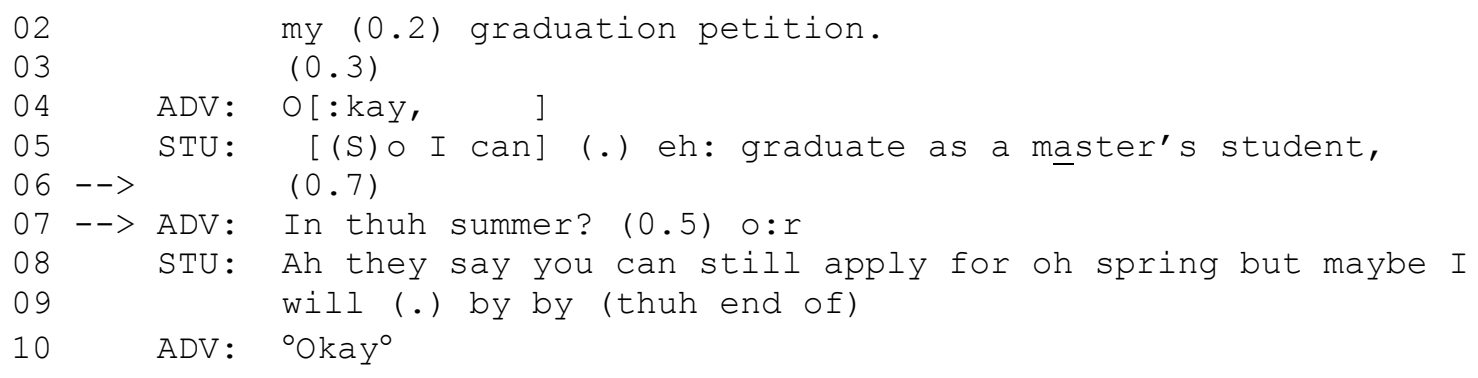

Stand-alone nodding can also be 'late,' as seen in Extract 20. The student comes to a cPCP after: “A:n' (0.7) there is another:, program, called ee tee e:m," (lines 3-4). After a very brief delay in the form of a micro-pause, “(.)" (line 4), the advisor responds by nodding and, simultaneously, the student solicits the advisor's understanding: "(I don't know if) you hear about that," (lines 5-6).

Extract 20: [\#2-\#5]

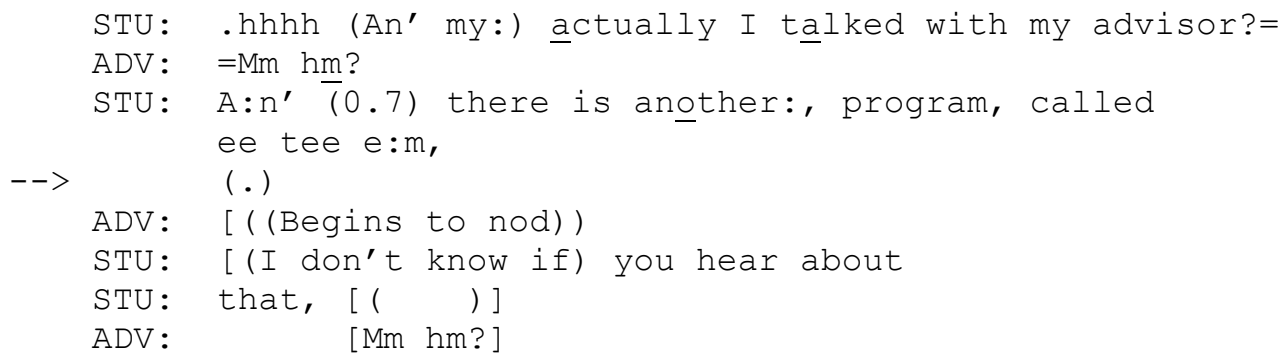

No response at all. In $10 \%$ of the cases (16/163), there was no response at all, vocal or non-vocal. Many of these cases are deviant and analyzed as such in more detail below. For two of these cases, see Extract 21.

Extract 21: [\#2-\#35]

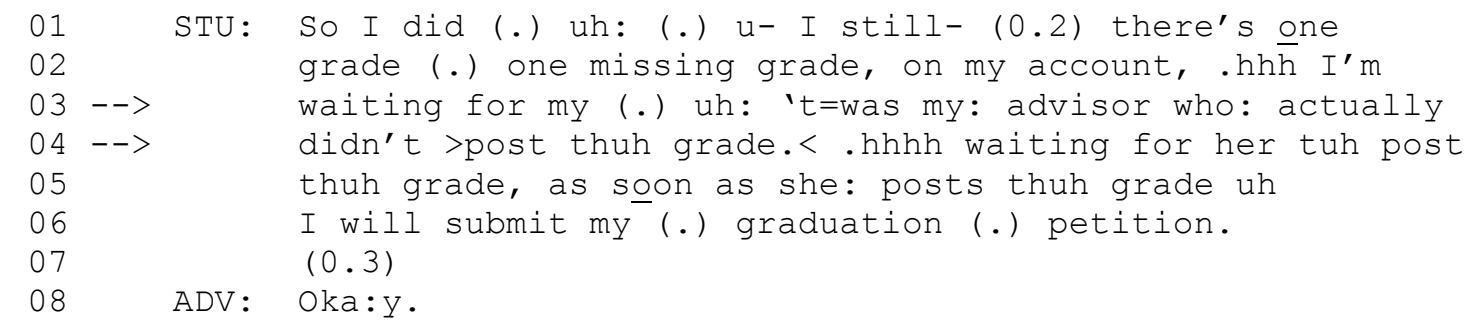


The student comes to a cPCP after both “there's one grade (.) one missing grade, on my account," (lines 1-2) and "“t=was my: advisor who: actually didn't >post thuh grade.” (lines 3-4). The advisor does not produce any type of response at, or around, either "account," or "grade."

\section{The Nature of Student Progression from Unit to Unit}

Related to the positioning of advisors' responses around cPCPs, I also documented the incidence of student progression after cPCPs. After bringing one unit to a cPCP, whether students do (or do not) progress their tellings is one form of evidence for whether students do (or do not) orient to advisors as having 'understood' the action implemented in the just-completed unit of talk. Students were considered to have progressed their presentations if, after bringing one unit to a $\mathrm{PCP}$, they continued speaking by: (1) producing a new turn-constructional unit; that (2) introduced or projected novel elements of background information; that (3) did not constitute repair. For example, in Extract 1 (above), the students' actions implemented through the units at lines $6,9-10,12,15,17-19,25$, and 27-30 were all considered to have progressed the presentation; however, this was not the case for the students' increment: "To sta:rt a job," (line 21; see discussion of increments below). Students progressed their tellings in $130 / 163$ cases $(79.75 \%)$.

Below I provide examples of the four types of student conduct that were not considered to constitute progression (these types were exhaustive of the data): (1) self repairs $(12 / 33 ; 36 \%)$; (2) understanding checks $(1 / 33 ; 03 \%)$; (3) increments to prior turnconstructional units (17/33; 52\%); and (4) answers to advisors' initiations of repair (i.e., repairs; 3/33; 09\%). 
Self repairs. Transition-space, self-initiated, self repairs (Schegloff, Jefferson, \& Sacks, 1977) represented cases in which students delayed the progression of their tellings in order to fix some problem with their 'speaking.' For example, see Extract 22. The student's unit "Uh:: (0.4) yeah. uh: (0.2) actually uh (0.2) uh: (.) .hhh I'm an international student (.) from India." (lines 3-4) comes to a cPCP after "India." (line 4).

Extract 22: [\#1-\#21]

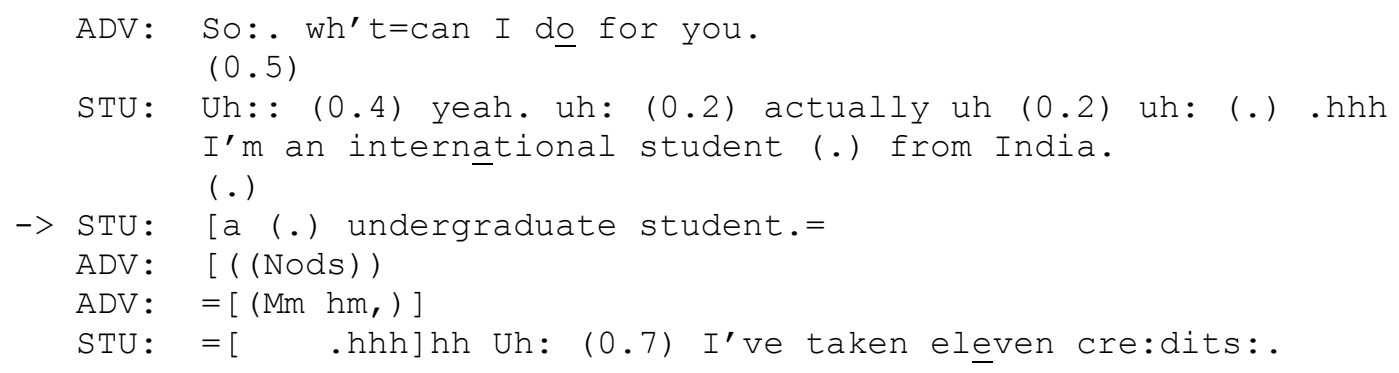

After a micropause at line 5-during which the advisor continues to gaze at the student, but otherwise does not respond vocally or with a nod - the student engages in self repair by producing, "a (.) undergraduate student." (line 6), which modifies and clarifies/specifies his previous characterization: "an international student" (Kitzinger, 2013). Simultaneous with the student's self repair, the advisor nods (line 7), which is thus responsive (albeit 'late' after the micropause at line 5; Jefferson, 1986) to the student's prior unit (at lines 3-4). Note that, precisely upon possible completion of the student's self repair (i.e., after "student."; line 6), the advisor responds with, “( $\mathrm{Mm} \mathrm{hm,)"} \mathrm{(line} \mathrm{8),}$ after which the student does progress his telling with: “Uh: (0.7) I've taken eleven cre:dits:." (line 9). An argument can be made that the student's self repair (line 6) is a practice here for soliciting a response from the advisor (Bolden, Mandelbaum, \& Wilkinson, 2012). 
Understanding checks. Students also delayed the progression of their tellings when they continued speaking by initiating sequences of talk designed to somehow check or confirm advisors' understandings of telling elements in immediately prior units. For example, see Extract 23. The student's unit “A:n' (0.7) there's another: (.) program (.) called ' $E$ ' ' $T$ ' ' $M$ '," (lines 9-10) comes to a cPCP after “" $E$ ' ' $T$ ' ' $M$ '," (which stands for Engineering and Technology Management).

Extract 23: [\#2-\#5]

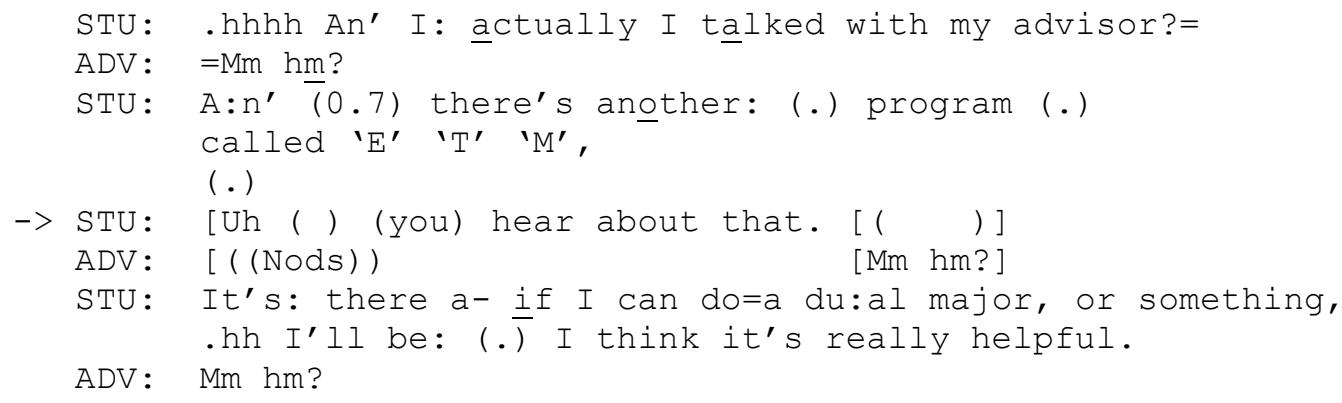

After a micropause at line 11 - during which the advisor continues to gaze at the student, but otherwise does not respond vocally or with a nod - the student requests confirmation that the advisor has 'heard' about the ETM program: "Uh ( ) (you) hear about that." (line 12). The advisor orients to this as such by confirming: "Mm $\mathrm{hm}$ ?" (line 13). Note that, immediately after the advisor's confirmation, "Mm hm?" (line 13), the student does progress his telling: "It's: there a- if I can do=a du:al major,..." (lines 14-15). Here the students' understanding check is an explicit practice for soliciting a response from the advisor.

Increments. Just over half of the cases $(17 / 33 ; 52 \%)$ constituting 'lack of progression' involved the addition of increments (Lerner, 2004; Schegloff, 2001 as cited in Stivers, 2008) to prior units. While increments may progress prior units (Lerner, 1996), 
increments delay the progression of the activity of telling insofar as they delay the production of new units headed toward the projected production of actionable problems.

For example, see Extract 24. The unit "As soon as she: posts thuh grade I will submit my (.) graduation (.) petition." (lines 10-11) comes to a cPCP after "petition." (line 11).

\section{Extract 24: [\#2-\#35]}

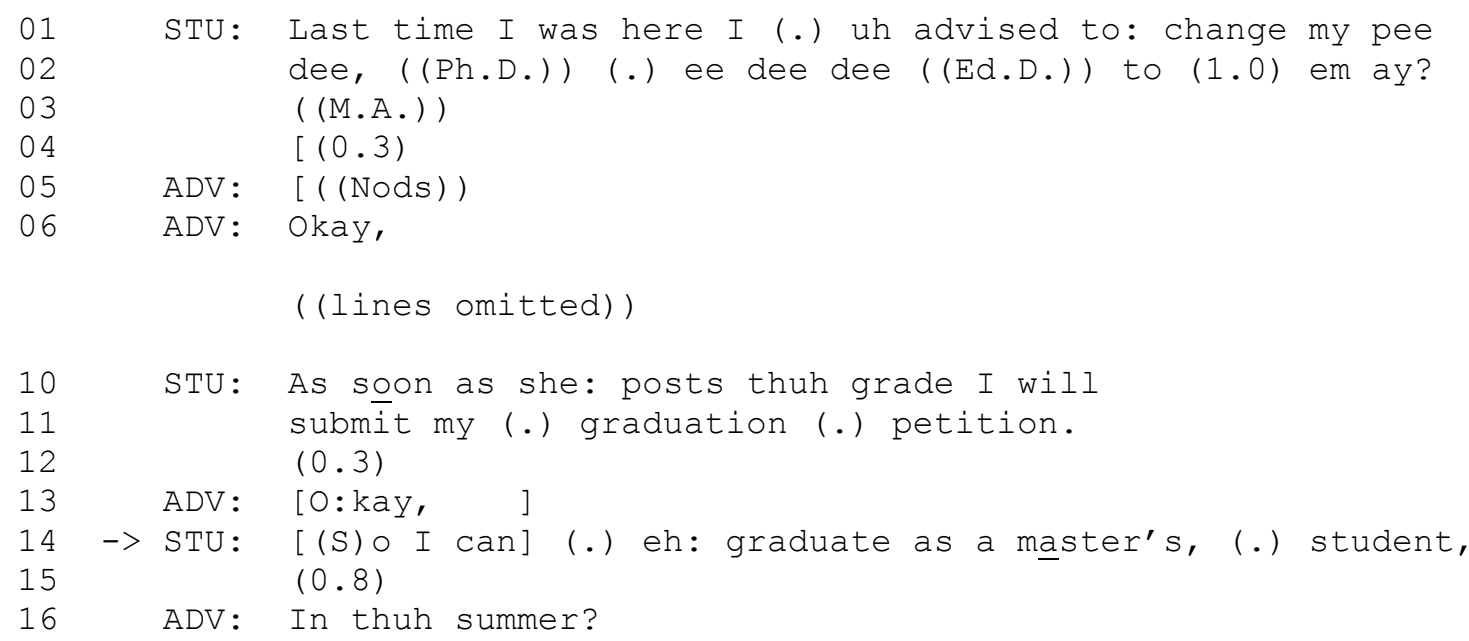

Figure 3a: Advisor's gaze at student

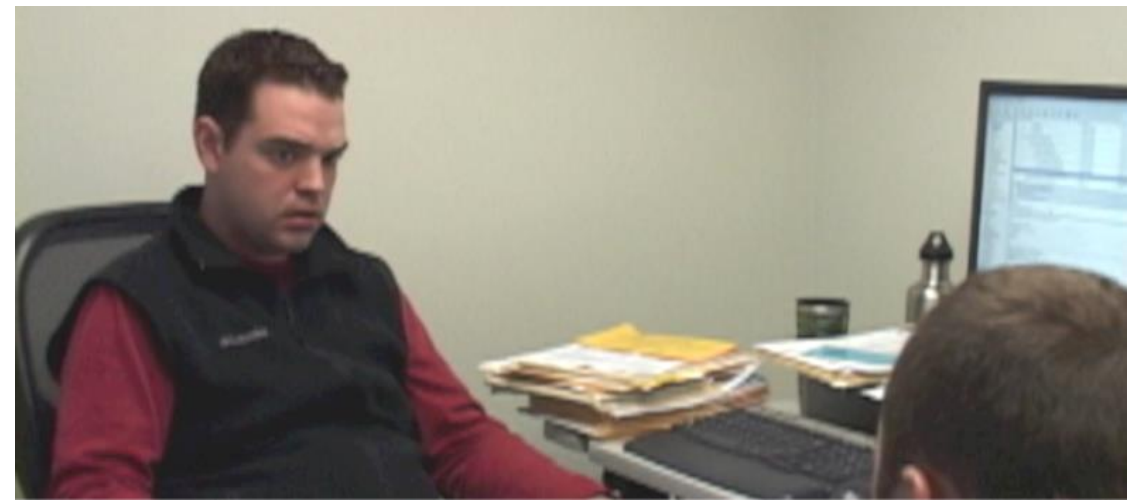


Figure 3b: Advisor's gaze shift

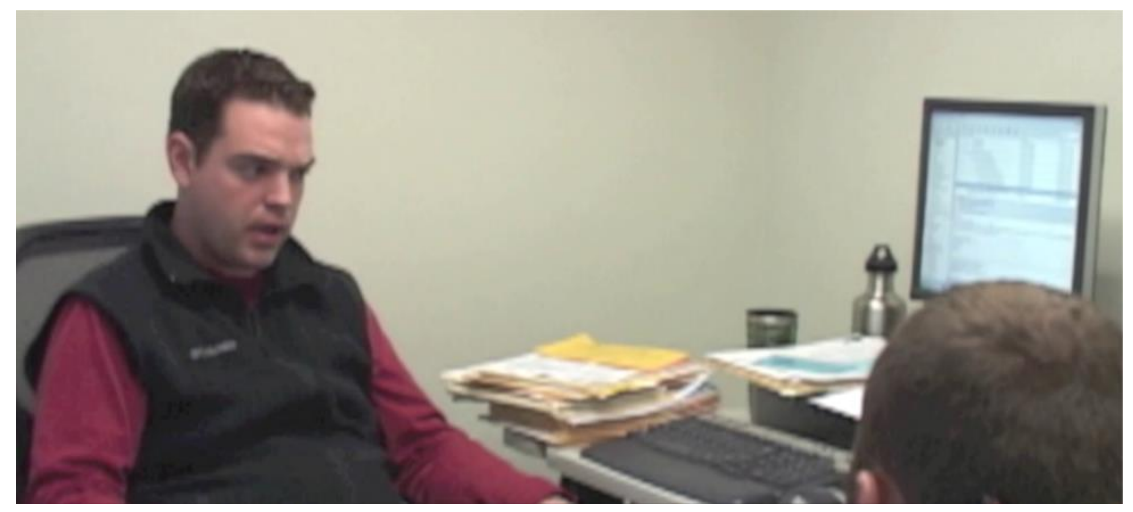

At line 12 there ensues a three-tenths of a second pause. During the first twotenths of a second, the advisor continues to gaze at the student (Figure 3a above), but otherwise does not respond vocally or with a nod. During the last one-tenth of a second, while keeping his head still, the advisor shifts his eyeballs to the left (Figure $3 \mathrm{~b}$ above), which can communicate 'thinking' or 'processing' (Argyle \& Cook, 1976), and thus may non-vocally index some type of 'trouble' (e.g., non-understanding). At line 14, the student adds the increment: “(S)o I can (.) eh: graduate as a master's, (.) student,". Insofar as the student has already indicated that he is receiving an "em ay?" (i.e., a M.A. or master's degree; line 2) and that they will be submitting a "graduation (.) petition" (line 11), the increment does much more to recapitulate already-presented information than to add new information. As Schegloff (in press) observed, increments positioned after an unmarked transition space (Jefferson, 1986) are typically "responsive to the absence of talk where talk by another was due" (Schegloff, in press, p. 21). In sum, it can be argued that the student's increment in Extract 24 (above, line 14) is a practice for soliciting and facilitating a response from the advisor (Bolden, Mandelbaum, \& Wilkinson, 2012). 
In some cases, students' increments were even more clearly mobilized toward repairing a type of 'failure' of recipiency (this is similar to the observation by Sacks, Schegloff, \& Jefferson, 1974, that tag questions can function to repair failures of turn transition; p. 724). For example, see Extract 25. As context, this session takes place at the end of the Spring term (June), which is the last of three terms in the formal, 9-month school year (Spring term is preceded by Fall and Winter terms), and the only term in which the university conducts graduation ceremonies. The student's unit at line 6, "So I'm graduating," comes to a cPCP after "graduating," if it is understood that the student is eligible to graduate after the adequate completion of the current school term.

Extract 25: [\#3-\#29]

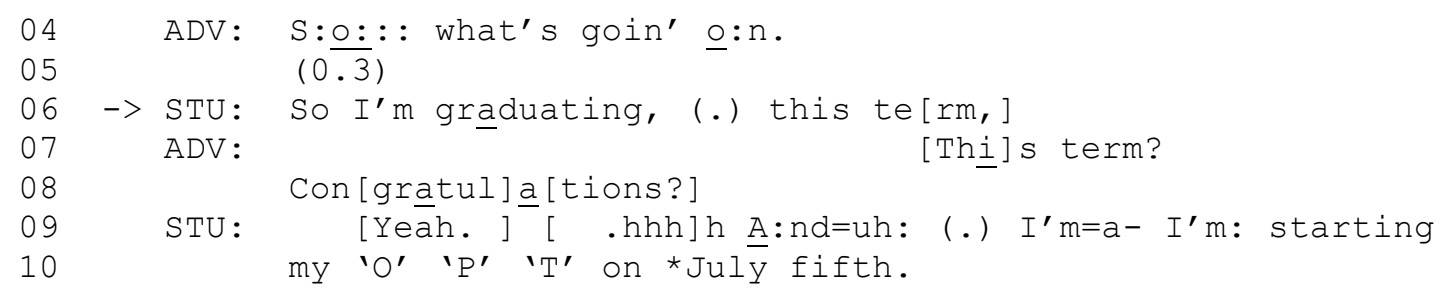

After a micropause, “(.)" (line 6) - during which the advisor continues to gaze at the student, but otherwise does not respond vocally or with a nod - the student adds the increment "this term," (line 6), which tacitly indexes the possible completion of her prior unit, "So I'm graduating," by clarifying his graduation timeline. This analysis is partially supported by the advisor's "This term?" (line 7; Note the vocal stress on "Thiss", symbolized in the transcript by underlining), which initiates repair on the student's prior unit, "So I'm graduating," by seeking clarification of the student's graduation timeline.

Answers to advisors' initiations of repair. Advisors' initiations of repair initiated sequences of talk that delayed the progression of students' tellings, and thus 
students' answers - that is, students' repairs - also constituted such delay. For example, see Extract 26 (below), which is a continuance of Extract 24 (above). The completion of the student's increment, “(S)o I can (.) eh: graduate as a master's, (.) student,” (line 13), brings their telling to another cPCP.

Extract 26: [\#2-\#35]

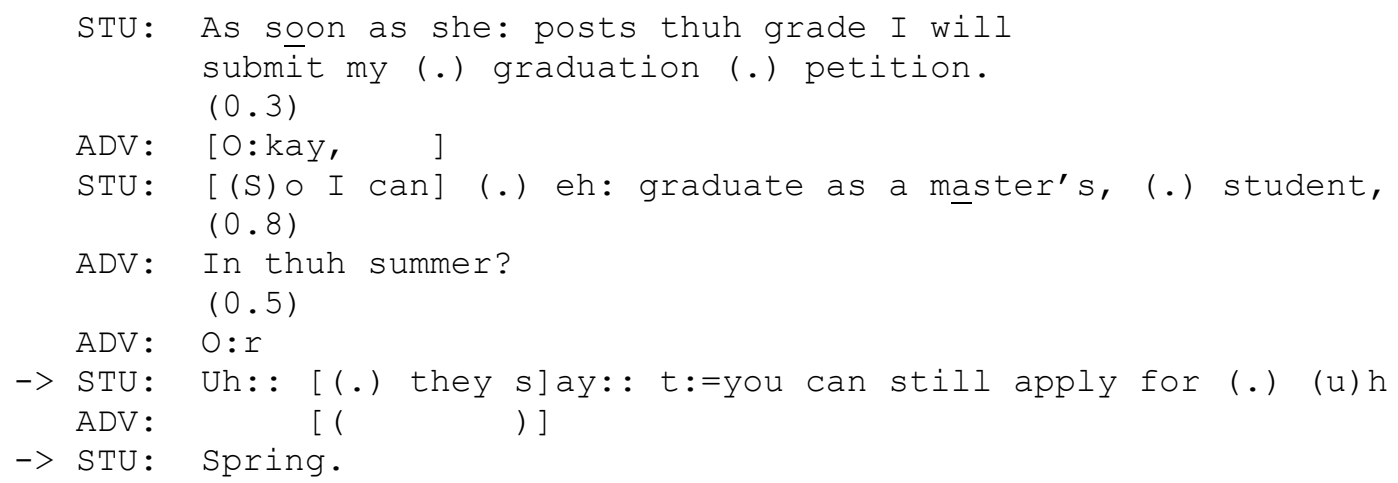

Figure 4: Advisor's gaze shift

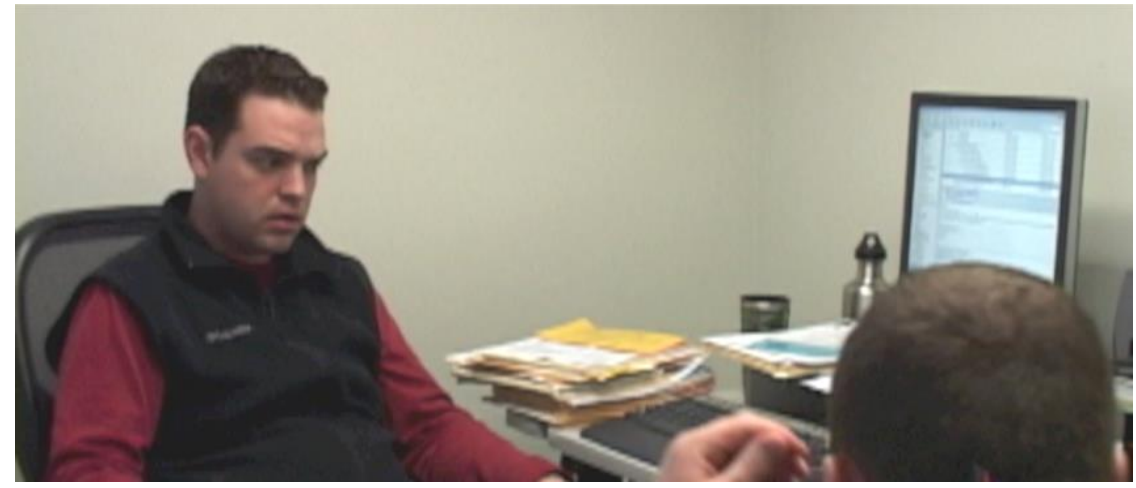

During the relatively long pause at line 14, the advisor's head and body remain oriented toward the student (see Figure 3a for before the advisor shifted his gaze), the advisor's eyeballs remain shifted to the left (possibly communicating 'thinking' or 'processing,' see Figure 4), and the advisor does not respond vocally or with a nod. 
Eventually, the advisor initiates repair: "In thuh summer? ... O:r" (lines 15-17). The student answers at lines 18-20, and this answer did not constitute activity progression.

\section{The Relationship Between Position of Advisor Response and Student Progression}

Table 5: Distribution of Cases Relative to Position of Advisor Response and Student Progression $(\mathrm{N}=163)$

\begin{tabular}{|c|c|c|c|}
\hline & $\begin{array}{c}\text { Student Does Progress } \\
\text { Telling }\end{array}$ & $\begin{array}{c}\text { Student Does Not } \\
\text { Progress Telling }\end{array}$ & Total \\
\hline $\begin{array}{c}\text { Advisor Response } \\
\text { Positioned Early or in } \\
\text { Transition Space }\end{array}$ & 119 & 10 & 129 \\
\hline $\begin{array}{c}\text { Row \% } \\
\text { Column \% } \\
\text { Total \% }\end{array}$ & $\begin{array}{l}92 \% \\
92 \% \\
73 \% \\
\end{array}$ & $\begin{array}{c}8 \% \\
30 \% \\
6 \% \\
\end{array}$ & \\
\hline $\begin{array}{c}\text { Advisor Response } \\
\text { Positioned Late or Not } \\
\text { at All }\end{array}$ & 11 & 23 & 34 \\
\hline $\begin{array}{l}\text { Row \% } \\
\text { Column \% } \\
\text { Total \% } \\
\end{array}$ & $\begin{array}{c}32 \% \\
8 \% \\
7 \% \\
\end{array}$ & $\begin{array}{l}68 \% \\
70 \% \\
14 \% \\
\end{array}$ & \\
\hline Total N & 130 & 33 & 163 \\
\hline
\end{tabular}

Table 5 displays the relationship between the positioning of advisors' responses (see the x-axis, involving 'early or within an unmarked transition space' or 'late or not at all') and whether or not students progressed their tellings after cPCPs (see the y-axis, involving 'progression' or 'lack of progression'). As seen in the upper-left quadrant, in 119/163 cases (73\% of all cases), advisors most commonly positioned their responses either early or within an unmarked transition space, and students progressed their tellings in their immediately next unit of talk (Extracts 14, 15, 16, and 17 fall into this upper-left 
quadrant). Of these 119 responses, 74 (62\%) were vocal continuers (e.g., $\mathrm{Mm} \mathrm{hm,} \mathrm{Uh}$ huh), 22 (18\%) were stand-alone nods, 15 (13\%) were Okay, 5 (04\%) were Yeah, 2 $(02 \%)$ were assessments, and $1(01 \%)$ was Right.

As seen in the lower-right quadrant, in 23/163 cases (14\% of all cases), advisors positioned their responses late relative to $\mathrm{cPCPs}$ (or did not produce any vocal or nodbased response) and students did not progress their tellings in their immediately next unit of talk; rather, students continued speaking by engaging in self repair, seeking confirmation of advisors' understandings, adding increments to prior units, or responding to advisors' repair initiators (Extracts 22, 23, 24, 25, and 26 fall into this lower-right quadrant).

The distribution of cases into these two (upper-left and lower-right) quadrants of Table 5 (i.e., $87 \%$ of all cases) directly support our argument that students orient to a relevance rule such that, at every $\mathrm{cPCP}$, advisors are accountable for producing some type of response that possibly indexes at least their attention to, if not their understanding of, students' immediately prior units. Specifically, when advisors produce such responses (upper-left quadrants of Table 5), students tend to progress their tellings, and when advisors do not (lower-right quadrants of Table 5), students tend to delay the progression of their telling activity in ways that at least provide advisors with 'second chances' (or even mandates) to respond (e.g., by producing self repairs or increments that provide new cPCPs, or by initiating requests for confirmation), and at most orient to advisors' 'lack' of responses as possibly indexing their trouble understanding. The disproportional distribution of cases into these two cells is statistically significant $\left(\mathrm{Chi}^{2}(1, \mathrm{~N}=163)=\right.$ 59.78; $p<.001$; Table 5). 
The social accountability of the proposed relevance rule is hyper-exposed in cases where: (1) advisors respond 'late;' (2) these responses claim 'no problem;' and (3) students nonetheless do not progress their tellings and orient to advisors' possible misunderstanding. For example, see Extract 27 (which is one of the cases located in the lower-right quadrant of Table 5, and thus 'of a set' with Extracts 22, 23, 24, 25, and 26 above). At lines 3-5, the students unit, "Uh:m (2.2) li:ke=h a week ago:? I got (.) thuh: (0.2) thuh (r)receipt,", comes to a cPCP after “(r)receipt," (line 5).

Extract 27: [\#3-\#16]

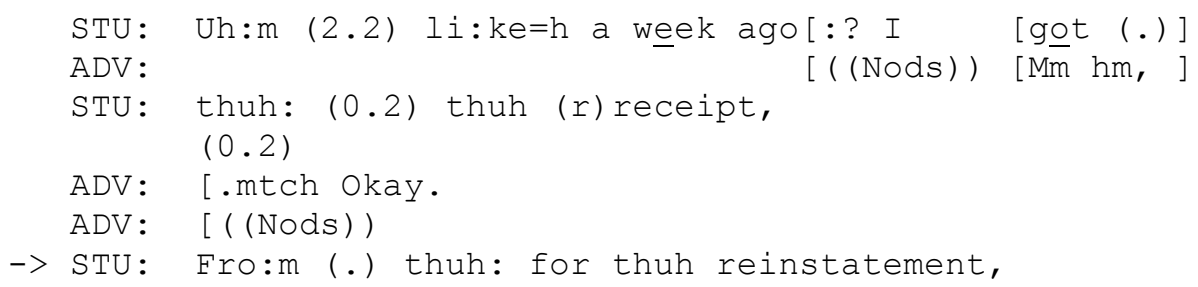

At line 6, the student pauses for two-tenths of a second, arguably 'making space' for the advisor's response, which comes 'late' (lines 7-8). The advisor's response, "Okay." (line 7), nominally claims to accept (Beach, 1995 Schegloff, 1982) - and tacitly claims to understand (Schegloff, 1982) - the student's prior informing. Had this Okay been positioned 'on time' (i.e., within an unmarked transition space), we might have expected the student to continue to progress his telling (as they did in Extracts 14, 15, 16, and 17 above). However, this Okay is not just any Okay, but a 'late' one. Thus, despite the advisor's nominal acceptance (lines 7-8), rather than progressing their telling, the student continues with an increment, "Fro:m (.) thuh: for thuh reinstatement," (line 9), which clarifies the nature of the "(r)receipt," (line 5), and thus orients to the advisor's 'late' response as possibly indexing their trouble understanding. 


\section{Deviant-Case Analyses}

There are, of course, possibly deviant cases that need to be addressed. In the lower-left quadrant of Table $5(11 / 163 ; 07 \%)$, in which advisors positioned their responses 'late' relative to $\mathrm{cPCPs}$ - or did not produce any vocal or nod-based response and students nonetheless progressed their tellings in their immediately next unit of talk. It turns out that 8 of these 11 cases are not deviant cases, but rather what Schegloff (1997) called 'boundary cases,' which “generally 'look like' our emerging phenomenon, even if they do not turn out to be instances of it" (p. 502). Boundary cases "are on both sides of the boundary, and in specifying the boundary, they help specify what belongs inside it and what does not" (p. 502, emphasis original). These 8 boundary cases are the only ones in the entire corpus in which students remove their gaze from advisors prior to, and during, $c P C P s$. Insofar as gaze communicates one's immediately current engagement with addressees (Goodwin, 1981), these cases instantiate a local non-engagement framework (i.e., projected by students' gaze orientation) within a more general participation framework (i.e., projected by students' body orientation; Goodwin, 1981). In line with this, in all 8 of these cases, advisors do not produce any type of response (i.e., vocal or nod). For example, see Extract 28. The student's unit, “Now this='s a very big mess which I ha:ve with me right now." (lines 76-77) comes to a cPCP after "now." (line 77).

Extract 28: [\#1-\#21]

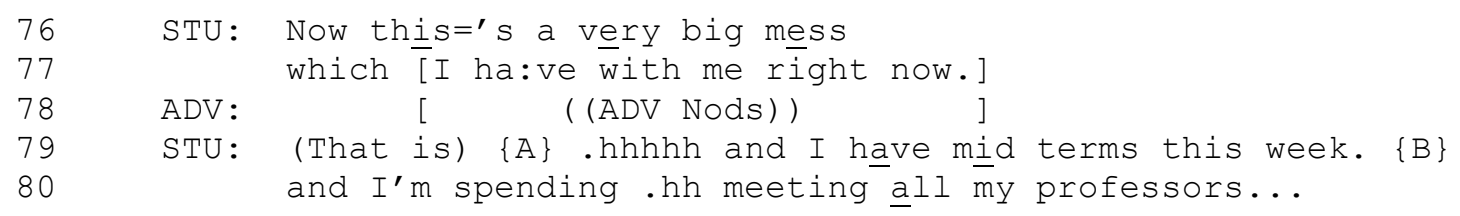


The student begins his next unit at line 79 gazing at the advisor (see Figure 5a, symbolized in the transcript as $\{\mathrm{A}\}$, which is positioned immediately before the student's inbreath: “.hhhhh”). As the student breaths in, “.hhhhh” (line 79), he begins to shift his head and gaze down and away to his left, culminating in Figure 5b (symbolized in the transcript as $\{\mathrm{B}\})$ in and through the cPCP after "week." (line 79). The advisor does not respond in any fashion, and the student immediately progresses his telling: "and I'm spending .hh meeting all my professors..." (line 80). In sum, in terms of the proposed relevance-rule, these 8 cases, as boundary (vs. core) cases, can be legitimately 'removed' from our analysis (which results in an even stronger statistical effect). It appears that the practice of students removing their gaze from advisors leading up to, and through, cPCPs is one for at least relaxing, if not lifting, the accountable relevance of advisors responding.

Figure 5a: Student gazing at advisor

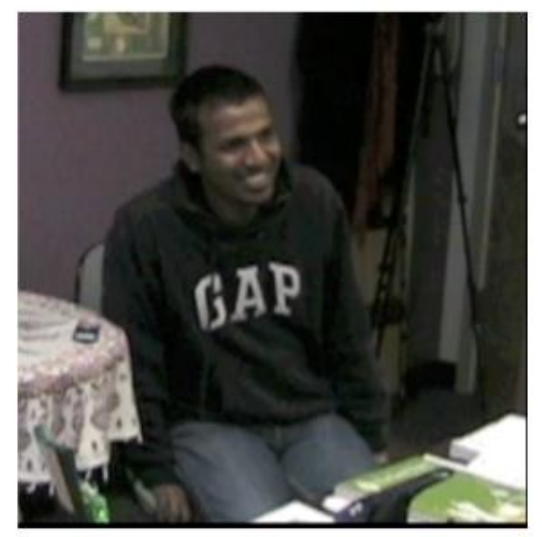

Figure 5b: Student gazing down and away to his left

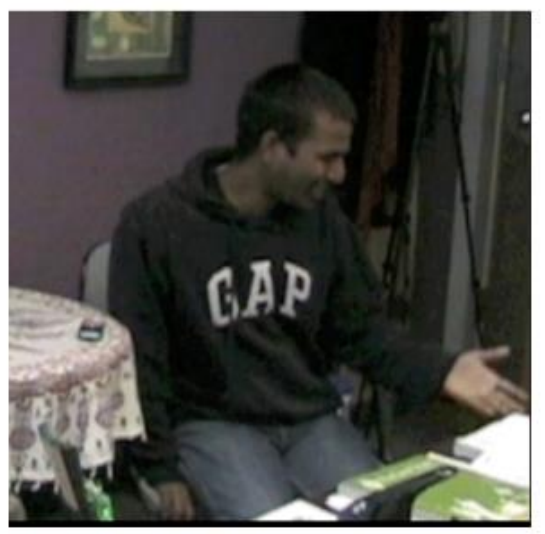

Continuing to deal with the lower-left quadrant of Table $5(11 / 163 ; 07 \%)$, the remaining 3/11 cases are deviant in that, while deviating from our proposed relevance rule, they nonetheless 'prove the rule.' For just one example, see Extract 29. The student's unit, "It's o:ne that's more secure." (line 16), comes to a cPCP after "secure." The advisor does not immediately respond - that is, the advisor begins to nod 'late' 
relative to the cPCP after ">an' li..." (line 16) - yet the student immediately progresses

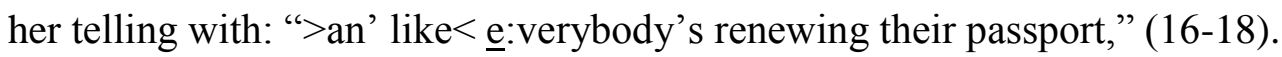

Extract 29: [\#1-\#14]

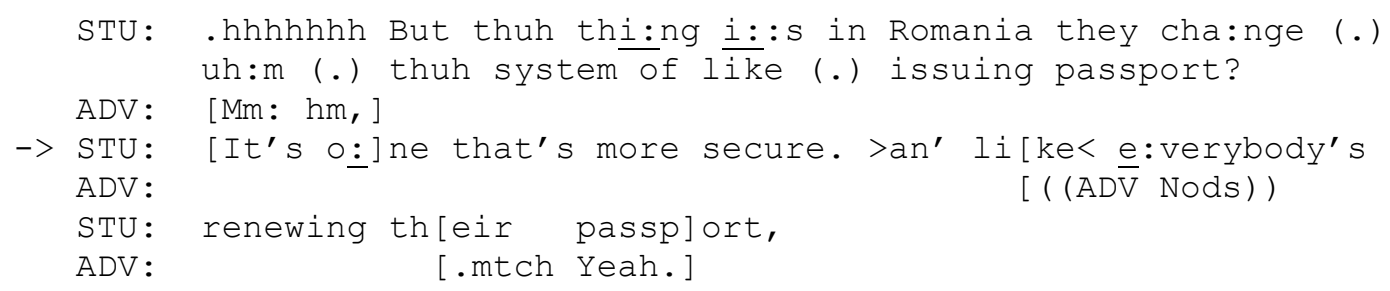

However, note that the advisor does, in fact, respond in line with our proposed relevance rule, that is, the advisor produces a stand-alone head nod at line 17. Furthermore, the 'lateness' of the advisor's response can be explained by the fact that the student produces " $>$ an' like $<$ " with a relatively quick pace (symbolized in the transcript with the inward-pointing carrot symbols), such that it is 'squeezed into' an 'unmarked' transition space (Jefferson, 1986; Schegloff, 1998b). Thus, an argument can be made that the advisor 'targeted' their nod at the unmarked transition space, and that this response was artificially coded as being 'late' due to the fast-paced start of the student's next unit.

The cases in the upper-right quadrant of Table $5(10 / 163 ; 06 \%)$ represents cases in which advisors responded either 'early' or within the unmarked transition space, yet students did not progress their tellings in their immediately next unit of talk. Almost all of these cases are deviant insofar as students' lack of progression can be independently explained in terms of a separate, and arguably more basic, set of rules organizing conversation (i.e., separate from our proposed relevance rule) involving repair. Specifically, research has demonstrated that speakers are accountable for 'speaking 
correctly' and, as such, they correct themselves despite claims of understanding by their recipients (Schegloff, 2007; Schegloff, Jefferson, \& Sacks, 1977).

For an example of self repair, see Extract 30. As context, international students must apply for, and receive, special permission to work in the United States. The student initially refers to this in terms of applying for their “...right of wo:rk." (line 5), after which occurs a cPCP.

\section{Extract 30: [\#1-\#14]}

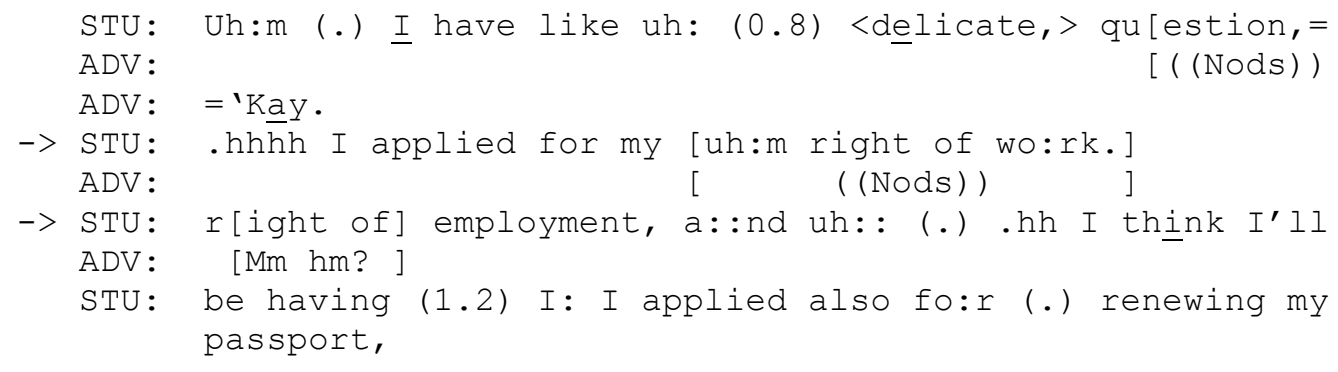

Although the advisor begins nodding at the onset of "uh:m" (line 5), and nods continuously through the unmarked transition space after "wo:rk." (line 5), the student does not progress her telling. Rather, the student immediately (i.e., within an unmarked transition space) engages in self-initiated, self repair (Schegloff, 2007; Schegloff, 2013; Schegloff, Jefferson, \& Sacks, 1977), replacing the less-official term 'work,' "right of wo:rk." (line 5), with the more-official term 'employment:' "right of employment," (line 7). Along these lines, note that the student's immediately preceding "uh:m" (line 5) occurs at a 'place of maximal grammatical control' (Schegloff, 1996b, p 93) and projects possible trouble finding an appropriate reference term (Goodwin \& Goodwin, 1986; Sacks, 1992; as cited in Lerner, 1996; Kitzinger, 2013). In sum, the deviancy of this case can be explained by the independent organization of self repair, which holds speakers 
accountable for 'speaking correctly' despite recipients' tacit claims of understanding (e.g., the advisor's head nod).

Cases in the upper-right quadrant of Table 5 also include instances where advisors initiate repair on students' prior units, and students' responses, by definition, do not constitute progression. For example, see Extract 31. The student's unit "now I take like part ti:me," (line 10) comes to a cPCP after "ti:me,".

Extract 31: [\#3-\#31]

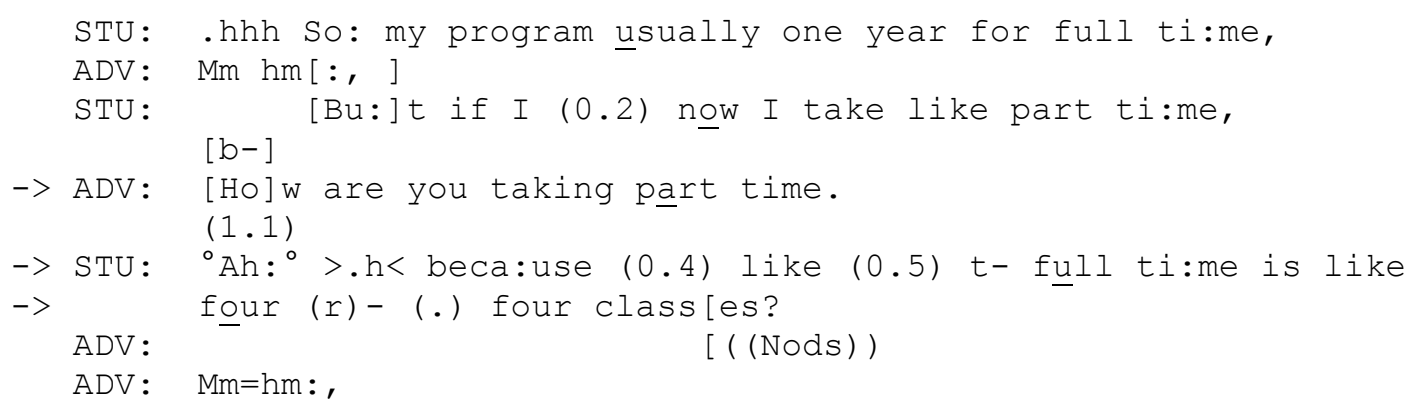

Immediately upon completion of the student's unit at line 10 (i.e., within an unmarked transition space), the advisor 'responds' by initiating repair: "How are you taking part time." (line 12). The advisor's repair initiator sequentially implicates an answer that does not constitute progression of the telling. Thus, the deviancy of this case can be explained sequence-organizationally by the repair-initiating nature of the advisor's 'response.'

In sum, cases like Extract 31 (above) do not stand as counter evidence to the proposed relevance rule. In each case, advisors do produce responses around cPCPs, and these responses are either 'early' or 'on time.' That students do not subsequently progress their tellings - and thus that these cases were coded in a particular fashion - can be 
independently explained by other organizations of conversation, such as those of repair and sequence. 


\section{Chapter 4}

\section{Discussion and Conclusion}

This thesis was originally motivated by a theorized applied problem in a particular context. This problem, if present, may have had possible deleterious consequences. The context was international-student advising. The anticipated problem was that, due to language barriers and the potential for cross-cultural misunderstanding, these advising sessions would be fraught with miscommunication. The possible deleterious consequences were that such miscommunication would reduce the efficacy of advising sessions, which are one (of many) resources that international students have to ease the burden and stressors associated with culture shock and adaptation. As such, this thesis set out to study the institutional context of native-English-speaking university advisors soliciting actionable questions/problems (e.g., What can I do for you today?) from nonnative, English-speaking international students. Furthermore, it was expected, a priori, that this thesis would focus on how these advising sessions would be hindered by 'understanding problems,' or breakdowns in intersubjectivty, especially ones driven by intercultural and/or language differences. However, the data 'told a different story.' Indeed, these data included very, very few understanding problems, virtually none of which had to do with intercultural and/or language differences. In some ways, the data challenge the relevance of the identity of 'non-native English speaker' in terms of it posing misunderstanding. Thus, the focus of this thesis shifted to analyzing how participants managed 'understanding.'

In every advising session, students 'answered' with projectably multi-unit tellings. On average, students' tellings consisted of 8 'middle' units involving the establishment of 
background information that led up to, and was projectably incomplete in terms of, the presentation of an actionable question/problem. This thesis examined these telling 'middles.' I argued for the existence of, and demonstrated, a relevance rule such that, at every complex possible-completion point (cPCP), advisors 'should' produce some type of 'acknowledging response,' including verbal (e.g., Okay), vocal (e.g., $\mathrm{Mm} \mathrm{hm}$ ), and non-vocal responses (i.e., head nods). This rule was supported distributionally, including an analysis of deviant cases. Furthermore, I demonstrated that both students and advisors orient to the violation of this rule as being accountable, such that the absence of a response is procedurally consequential (Schegloff, 1992) and generative of secondarily elaborative inferences (Heritage, 1990). Specifically, the absence of a response was treated as indexing (tacitly or explicitly) advisors' possible trouble understanding students' immediately prior units/actions. It is by reference to this relevance rule that both participants - that is, both advisors and students - manage understanding, at least in part. That is, by responding with a range of minimal-acknowledgements (e.g., continuers, stand-alone head nods, Okay, etc.) at least 'on time' relative to cPCPs, advisors are able to claim (if not demonstrate) that they understood students' prior units/actions, and students treated advisors in this manner by progressing their tellings. By responding 'late' relative to cPCPs, advisors are able to claim possible trouble understanding students' prior units/actions, and students treated advisors in this manner by not progressing their tellings by variously repairing or clarifying prior units/actions.

The possible existence of such a relevance rule is striking because it is not at all obvious given at least the following four facts. First and foremost, the actions that students implement in the 'middles' of their presentations are projectably non-sequence 
terminal. That is, both advisors and students arguably understand that, upon completion of middle units, students hold the rights to continue speaking. Thus, there is no prima facie sequential relevance that advisors 'should respond.' Second, students' actions are addressed to advisors who are already claiming full, or uncontaminated, attention with both their gaze and body orientation (see Figure 2a, above). Third, even in the context of extended tellings, the rules for turn taking still pressure advisors to 'listen' (Sacks, Schegloff, \& Jefferson, 1974). Fourth, at least in ordinary, telephone conversation (which is admittedly different from the present, face-to-face, institutional data), there is evidence that, in the context of multi-unit turns, responsive behavior at the possible completion of each and every turn-constructional unit is not necessary for the maintenance of intersubjectivity (Robinson, 2014).

\section{Limitations}

Although I believe I have found something (i.e., a relevance rule), explaining it is extremely difficult given the lack of previously published, comparable analyses in either ordinary or institutional contexts. As noted in the introduction, prior literature has given the middles of projectably extended tellings short shrift relative to their beginnings and endings. Within literature on such middles, there has been no systematic analyses of the occurrence of responsive behavior, that is, analyses of: (1) many tellings (vs. a single, or even several, tellings); (2) when responsive behavior does, and does not, occur at the possible completion of each and every middle unit; and (3) where responsive behavior is positioned relative to cPCPs. Complicating this are my findings regarding non-vocal conduct: (1) The most common type of responsive behavior by advisors (22\%) was the stand-alone head nod; (2) Advisors' nodding was part and parcel of 56\% of their vocal 
responsive behavior; and (3) Students' and advisors' gaze orientation toward or away from each other, which did not always correspond to shifts in the orientations of their heads, altered their participation framework (Goodwin, 1981), which affected the relevance of responsive behavior. In order to adequately analyze this non-vocal phenomena, not only is videotape data necessary (which I had), but more importantly, multiple camera angles are necessary (which I also had), as these angles allow researchers to rigorously defend claims about non-vocal behavior (e.g., that the student was, in fact, gazing at the advisor and thus able to witness their behavior, that the advisor's nod was, in fact, a nod, etc.) (Mondada, 2013; Rossano, 2013). Unfortunately, prior literature on projectably extended tellings has not utilized multiple camera angles in this way, comparison and explanation of my findings are virtually impossible.

Perhaps the proposed relevance rule applies in analogous institutional activities, such as patients' projectably multi-unit problem presentations to physicians (e.g., Heath, 1981; Heritage \& Robinson, 2006a, 2006b; Maynard \& Heritage, 2005; Robinson, 1998, 2006; Robinson \& Heritage, 2005, 2006), and perhaps it also applies in analogous ordinary activities, such as stories that are 'solicited' by friends and family members (Mandelbaum, 2013). I just do not know yet and, as such, it seems premature to venture into explanations for, and implications of, my findings, all of which would be grossly speculative because they would lack comparative grounding. What is clear is that such grounding needs to be done, with prospective payoffs for our understanding of the organization of turn taking, of how participants manage intersubjectivity, and of procedurally consequential inferential frameworks (Drew \& Heritage, 1992, as cited in Peräkylä, 2013) instantiated by particular activities, institutional or otherwise. 
This study has a number of limitations. First, the sample size is relatively small ( $N=20$ advising sessions and $163 \mathrm{cPCPs}$ ), which can threaten validity. Second, I only examined complex possible-completion places (i.e., places where units were possibly complete grammatically, intonationally, and pragmatically), and thus my findings do not necessarily generalize to other types of possible-completion (e.g., solely grammatical, or only grammatical and pragmatic, etc.). Third, data were collected from a single university, and from a distinct dyadic population (i.e., non-native, English-speaking, international students seeking advice from native-English speaking advisors), and thus my findings may not generalize to broader or more varied populations. Fourth, I only focused on one discrete 'activity' - that is, the 'problem presentation' phase of advising encounters - and my findings do not necessarily generalize beyond that activity. Fifth, the limited statistical associations were non-parametric and non-correlational, which prevented an exploration of a range of unmeasured or confounding 'variables' that might have been associated with advisors' responsiveness, such as demographics. Sixth, along these lines, data did not include a control group, for example, of native-English-speaking students, which limits comparative claims. Seventh, the mere presence of video cameras may have influenced participants' behavior (e.g., Labov's (1972) observers' paradox as cited in Mondada (2013), which is a variant of Henry Landsberger's (1955) Hawthorne effect).

In conclusion, this thesis is perhaps the first to document and defend a relevance rule that systematically organizes at least the 'middles' of a specific type of projectably, multi-unit tellings. Relevance rules involve both normative structures of reasoning and normative patterns of conduct. It is important to understand relevance rules because they 
tend to be cloaked in the deep structure of interaction, rarely being exposed on its surface, yet they massively affect conduct and its interpretation. 


\section{References}

Allen, D., \& Guy, R. (1974). Conversation analysis: The sociology of talk. The Hague, The Netherlands: Mouton.

Argyle, M., \& Cook, M. (1976). Gaze and mutual gaze. Cambridge, England: Cambridge University Press.

Atkinson, J. M., \& Heritage, J. (Eds.), (1984). Structures of social action: Studies in conversation analysis. Cambridge, England: Cambridge University Press.

Bardovi-Harlig, K., \& Hartford, B. S. (1993). Learning the Rules of Academic Talk: A Longitudinal Study of Pragmatic Change. Studies in Second Language Acquisition, 15, 279-304.

Beach, W. A. (1995). Presenting and constraining options: 'Okay" and 'official' priorities in medical interviews. In G. H. Morris \& R. J. Chenail (Eds.), Talk of the clinic: Explorations in the analysis of medical and therapeutic discourse (pp. 259-289). Hillsdale, NJ: Lawrence Erlbaum.

Beamer, L., \& Varner, I. I. (2005). Intercultural communication in the global workplace. Boston, MA: McGraw-Hill.

Bolden, G. B., Mandelbaum, J., \& Wilkinson, S. (2012). Pursuing a response by repairing an indexical reference. Research on Language and Social Interaction, 45, 137155.

Cadieux, R. A. J., \& Wehrly, B. (1986). Advising and counseling the international student. New Directions for Student Services, 36, 51-63.

Clancy, P. M., Thompson, S. A., Suzuki, R., \& Hongyin, T. (1996). The conversational use of reactive tokens in English, Japanese, and Mandarin. Journal of Pragmatics, 
26, 355-387.

Clark, H. H. (1996). Using language. Cambridge, England: Cambridge University Press.

Clayman, S. E., \& Gill, V. T. (2004). Conversation analysis. In M. Hardy \& A. Bryman, (Eds.), Handbook of data analysis (pp. 589-606). Thousand Oaks, CA: Sage Publications Inc.

Dittmann, A. T., \& Llewellyn, L. G. (1968). Relationship between vocalizations and head nods as listener responses. Journal of Personality and Social Psychology, 9, 7984.

Drew, P., \& Heritage, J. (1992). Analyzing talk at work: An introduction. In P. Drew \& J. Heritage (Eds.), Talk at work: Interaction in institutional settings. Cambridge, England: Cambridge University Press.

Drummond, K., \& Hopper, R. (1993). Back channels revisited: Acknowledgment tokens and speakership incipiency. Research on Language and Social Interaction, 26, $157-178$.

Duranti. A. (1986). The audience as co-author: An introduction. Text, 6, 239-247.

Ford, C., Fox, B., \& Thompson, S. A. (2002). Constituency and the grammar of turn increments. In C. Ford, B. Fox \& S. A. Thompson (Eds.), The language of turn and sequence (pp. 14-38). Oxford, England: Oxford University Press.

Ford, C., \& Thompson, S. A. (1996). Interactional units in conversation: Systematic, intonational, and pragmatic resources for the management of turns. In E. Ochs, E. A. Schegloff, \& S. A. Thompson (Eds.), Interaction and grammar (pp. 134-184). Cambridge, England: Cambridge University Press.

Gardner, R. (2001). When listeners talk: Response tokens and listener stance. 
Amsterdam: John Benjamins Publishing Company.

Giles, H., \& Noels, K. A. (2002). Communication accommodation in intercultural encounters. In J. N. Martin, T. K. Nakayama, \& L. A. Flores (Eds.), Readings in cultural contexts (pp. 117-126). Boston, MA: The McGraw-Hill Higher Education.

Goffman, E. (1981). Footing. In E. Goffman (Ed.), Forms of talk (pp. 124-159). Philadelphia, PA: University of Pennsylvania Press.

Goodwin, C. (1981). Conversational organization: Interaction between speakers and hearers. New York, NY: Academic Press.

Goodwin, C. (1984). Notes on story structure and the organization of participation. In J. M. Atkinson \& J. Heritage (Eds.), Structures of social action (pp. 225-246). Cambridge, England: Cambridge University Press.

Goodwin, C. (1986a). Audience diversity, participation and interpretation. Text, 6, 283-316.

Goodwin, C. (1986b). Between and within: Alternative Sequential treatments of continuers and assessments. Human Studies, 9, 205-217.

Goodwin, C. (1986c). Gestures as a resource for the organization of mutual orientation. Semiotica, 62, 29-49.

Goodwin, M. H. (1997). Byplay: Negotiating evaluation in storytelling. In G. R. Guy, C. Feagin, D. Schiffrin, \& J. Baugh (Eds.), Towards a social science of language: Papers in honor of William Labov (Vol. 2, pp 77-102). Amsterdam, The Netherlands: John Benjamins.

Gudykunst, W. B. (1998). Understanding cultural differences. In Bridging differences: Effective intergroup communication (pp. 40-69). Thousand Oaks, CA: Sage 
Publications.

Gudykunst, W. B. (2001). Communication and ethnicity. In Asian American ethnicity and communication (pp. 1-15). Thousand Oaks, CA: Sage Publications.

Gudykunst, W. B., \& Kim, Y. Y. (1997). Communicating with strangers (3rd ed.). New York, NY: McGraw-Hill.

Guthrie, A. M. (1997). On the systematic deployment of okay and mmhmm in academic advising sessions. Pragmatics, 7, 397-415.

Hall, E. T., \& Hall, M. R. (2002). Key concepts: Underlying structure of culture. In J. N. Martin, T. K. Nakayama, \& L. A. Flores, (Eds.), Readings in intercultural communication: Experiences and contexts (pp. 165-172). Boston, MA: The McGraw-Hill Higher Education.

Halkowski, T. (2006). Realizing the illness: Patients' narratives of symptom discovery. In J. Heritage \& D. W. Maynard (Es.), Communication in medical care: Interaction between primary care physicians and patients (pp. 86-114). Cambridge, England: Cambridge University Press.

Hammons, L., Lee, Y., Akins, R., Somasundaram, U. V., \& Egan, T. M. (2004). An evaluation case study of an international student services office: Assessing satisfaction and productivity. Texas: Texas A\&M University. (ERIC Document Reproduction Service No. ED 492110).

Hayes, R. L., \& Lin, H. (1994). Coming to America: Developing social support systems for international students. In Journal of Multicultural Counseling \& Development. $22,7-16$.

Heath, C. (1981) The opening sequence in doctor-patient interaction. In P. Atkinson \& C. 
Heath (Eds.), Medical work: Realities and routines (pp. 71-90). Farnborough, England: Gower.

Heath, C., \& Luff, P. (2013). Embodied action and organizational activity. In J. Sidnell and T. Stivers (Eds.), The handbook of conversation analysis (pp. 283-307). Malden, MA: Wiley-Blackwell.

Hepburn, A., \& Bolden, G. B. (2013). The conversation analytic approach to transcription. In J. Sidnell and T. Stivers (Eds.), The handbook of conversation analysis (pp. 57-76). Malden, MA: Wiley-Blackwell.

Heritage, J. (1984). Garfinkel and ethnomethodology. Cambridge, England: Polity Press. Heritage, J. (1990). Interactional accountability: A conversation analytic perspective. In B. Conein, M. de Fornel, \& L. Quere (Eds.), Les formes de la conversation (Vol. 1, pp. 23-49). Paris: CNET.

Heritage, J. (2004). Conversational analysis and institutional talk. In R. Sanders and K. Fitch (Eds), Handbook of language and social interaction (pp. 103-146). Mahwah, NJ: Eribaum.

Heritage, J., \& Robinson, J. D. (2006a). Accounting for the visit: Giving reasons for seeking medical care. In J. Heritage \& D. W. Maynard (Eds.), Communication in medical care: Interaction between primary care physicians and patients (pp. 4885). Cambridge, England: Cambridge University Press.

Heritage, J., \& Robinson, J. D. (2006b). The structure of patients' presenting concerns: Physicians' opening questions. Health Communication, 19, 89-102.

Hutchby, I., \& Wooffitt, R. (1998). Talk in institutional settings. In Conversation analysis. (pp. 145-171). Cambridge, England: Polity Press. 
Institute of International Education (2013). Open doors 2013 data. Retrieved from http://www.iie.org/Research-and-Publications/Open-Doors/Data/International$\underline{\text { Students/Enrollment-Trends/1948-2012 }}$

Iwasaki, S. (2009). Initiating Interactive Turn Spaces in Japanese Conversation: Local Projection and Collaborative Action. Discourse Processes, 46, 226-246.

Jefferson, G. (1978), Sequential aspects of storytelling in conversation. In J. Schenkein (Ed.) Studies in the organization of conversational interaction (pp.219-248). New York, NY: Academic Press.

Jefferson, G. (1984). Notes on a systematic deployment of the acknowledgement tokens 'Yeah' and 'Mmhm'. Paper in Linguistics, 17, 197-216.

Jefferson, G. (1986). Notes on 'latency' in overlap onset. Human Studies, 9, 153-183.

Jefferson, G. (2004). Glossary of transcript symbols with an Introduction. In G. H. Lerner (Ed.), Conversation analysis: Studies from the first generation (pp. 13-31). Philadelphia, PA: John Benjamins.

Kasper, G., \& Prior, M. T. (2015). Analyzing storytelling in TESOL interview research. TESOL Quarterly, 49, 226-255.

Kidwell, M. (2000). Common ground in cross-cultural communication: Sequential and institutional contexts in front desk service encounters. Issues in Applied Linguistics, 11, 17-37.

Kita, S., \& Ide, S. (2007). Nodding, aizuchi, and final particles in Japanese conversation: How conversation reflects the ideology of communication and social relationships. Journal of Pragmatics, 39, 1242-1254.

Kitzinger, C. (2013). Repair. In J. Sidnell and T. Stivers (Eds.), The handbook of 
conversation analysis (pp. 229-256). Malden, MA: Wiley-Blackwell.

Kogure, M. (2007). Nodding and smiling in silence during the loop sequence of backchannels in Japanese conversation. Journal of Pragmatics, 39, 1275-1289.

Labov, W. (1972). Language in the inner city: Studies in the Black English vernacular. Philadelphia, PA: University of Pennsylvania Press.

Labov, W., \& Waletzky, J. (1967). Narrative analysis: Oral versions of personal experience. In J. Helm (Ed.), Essays on the verbal and visual arts (pp. 12-44). Seattle, WA: University of Washington Press.

Lambertz, K. (2011). Back-channeling: The use of yeah and mm to portray engaged listenership, Griffith Working Papers in Pragmatics and Intercultural Communication, 4, 11-18.

Lee, M., Abd-Ella, M., \& Burke, L. (1981). Need of foreign students from developing nations at U.S. colleges and universities. Washington, D.C.: National Association for Foreign Student Affairs.

Lerner, G. H. (1996). On the "semi-permeable" character of grammatical units in conversation: Conditional entry into the turn space of another speaker. In E. Ochs, E. A. Schegloff, \& S. Thompson (Eds.), Interaction and grammar, (pp. 238-276). Cambridge, England: Cambridge University Press.

Levinson, S. C. (1979). Activity types and language. Linguistics, 17, 365-399.

Levinson, S. C. (2013). Action formation and ascription. In J. Sidnell and T. Stivers (Eds.), The handbook of conversation analysis (pp. 104-130). Malden, MA: Wiley-Blackwell.

Liddicoat, A. J. (2004). The projectability of turn constructional units and the role of 67 
prediction in listening. Discourse Studies, 6, 449-470.

Liddicoat, A. J. (2007). An introduction to conversation analysis. London, England: Continuum.

MacNealy, M. S. (1999). Strategies for empirical research in writing. New York, NY: Longman.

Mandelbaum, J. (1987). Couples sharing stories. Communication Quarterly, 35, 144170.

Mandelbaum, J. (1989). Interpersonal activities in conversational storytelling. Western Journal of Speech Communication, 53, 114-126.

Mandelbaum, J. (1993). Assigning responsibility in conversational storytelling: The interactional construction of reality. Text, 13, 247-266.

Mandelbaum, J. (2003). Interactive methods for constructing relationships. In P. Glenn, C. D. LeBaron, \& J. Mandelbaum (Eds.), Studies in language and social interaction. In honor of Robert Hopper (pp. 207-220). Mahwah, NJ: Lawrence Erlbaum.

Mandelbaum, J. (2010). Concurrent and intervening actions during storytelling in family 'ceremonial' dinners. In D. Schiffrin, A. De Fina \& A. Nylund (Eds.), Telling stories: Language, narrative, and social life (pp. 161-172). Washington, DC: Georgetown University Press.

Mandelbaum, J. (2013). Storytelling in conversation. In Sidnell, J. \& Stivers, T. (Eds.) The handbook of conversation analysis (pp. 492-508). Malden, MA: WileyBlackwell. 
Martin, J. N., Nakayama, T. K., \& Flores, L. A. (Eds.). (2002). Readings in intercultural communication: Experiences and contexts. Boston, MA: The McGraw-Hill Higher Education.

Maynard, D. W., \& Heritage, J. (2005). Conversation analysis, doctor-patient interaction and medical communication. Medical Education, 39, 428-435.

Maynard, S. (1990). Conversation management in contrast: Listener response in Japanese and American English. Journal of Pragmatics, 14, 397-412.

Maynard, S. (1997). Analyzing interactional management in native/non-native English conversation: A case of listener response, International Review of Applied Linguistics, 35, 37-60.

Mondada, L. (2013). The conversation analytic approach to data collection. In J. Sidnell \& T. Stivers (Eds.), The handbook of conversation analysis (pp. 32-56). Malden, MA: Wiley-Blackwell.

Oreström, B. (1983). Turn-taking in English conversation. Lund, Sweden: CWK Gleerup. Peräkylä, A. (1997). Reliability and validity in research based on tapes and transcripts. In D. Silverman (Ed.), Qualitative research: Theory, method and practice (pp. 201220). London, England: Sage.

Peräkylä, A. (2013). Conversation analysis in psychotherapy. In J. Sidnell \& T. Stivers (Eds.), The handbook of conversation analysis (pp. 551-574). Malden, MA: Wiley-Blackwell.

Perruci, R., \& Hu, H. (1995). Satisfaction with social and educational experiences among international graduate students. Research in Higher Education, 36, 491-508. 
Roberts, F., \& Robinson, J. D. (2004). Interobserver agreement on first-stage conversation analytic transcription. Human Communication Research, 30, 376-410.

Robinson, J. D. (1998). Getting down to business: Talk, gaze, and body orientation during openings of doctor-patient consultations. Human Communication Research, 25, 97-123.

Robinson, J. D. (2003). An interactional structure of medical activities during acute visits and its implications for patients' participation. Health Communication, 15, 27-57.

Robinson, J. D. (2006). Soliciting patients' presenting concerns. In J. Heritage \& D. Maynard (Eds.), Communication in medical care: Interaction between primary care physicians and patients (pp. 22-47). Cambridge, England: Cambridge University Press.

Robinson, J. D. (2007). The role of numbers and statistics within conversation analysis. Communication Methods and Measures, 1, 65-75.

Robinson, J. D. (2013). Epistemics, action formation, and other-initiation of repair: The case of partial questioning repeats. In J. Sidnell, M. Hayashi, \& G. Raymond (Eds.), Conversational repair and human understanding (pp. 261-292). Cambridge, England: Cambridge University Press.

Robinson, J. D. (2014). What "What?" tells us about how conversationalists manage intersubjectivity. Research on Language and Social Interaction, 47, 109-129.

Robinson, J. D., \& Heritage, J. (2005). The structure of patients' concerns: The completion relevance of current symptoms. Social Science \& Medicine, 61, 481- 493.

Robinson, J. D., \& Heritage, J. (2006). Physicians' opening questions and patients' 
satisfaction. Patient Education and Counseling, 60, 279-285.

Rossano, F. (2013). Gaze in conversation. In J. Sidnell, \& T. Stivers (Eds.), The handbook of conversation analysis (pp. 308-329). Malden, MA: Wiley-Blackwell.

Ruusuvuori, J. (2001). Looking means listening: Coordinating displays of engagement in doctor-patient interaction. Social Science \& Medicine, 52, 1093-1108.

Sacks, H. (1972). On the analyzability of stories by children. In J. J. Gumperz \& D. Hymes (Eds.), Directions in sociolinguistics: The ethnography of communication (pp. 325-345). New York, NY: Holt, Rinehart and Winston.

Sacks, H. (1974). An analysis of the course of a joke's telling in conversation. In R. Bauman \& J. Sherzer (Eds.), Explorations in the ethnography of speaking (pp. 337-353). Cambridge, England: Cambridge University Press.

Sacks, H. (1987). On the preferences for agreement and contiguity in sequences in conversation. In G. Button \& J. R. Lee (Eds.), Talk and social organisation (pp. 54-69). Clevedon, England: Multilingual Matters.

Sacks, H. Schegloff, E. A., \& Jefferson, G. (1974). A simplest systematics for the organization of turn-taking for conversation. Language, 50, 696-735.

Saiga, H., Sumi, Y., \& Nishida, T. (2011). Function analysis of head nodding in multiparty conversations. Retrieved from http://www.interactionipsj.org/archives/paper2011/interactive/0300/1CR3-5.pdf

Schegloff, E. A. (1968). Sequencing in conversational openings. American Anthropologist, 70, 1075-1095.

Schegloff, E. A. (1972). Notes on a conversational practice: Formulating place. In D. Sudnow (Ed.), Studies in social interaction (pp. 75-119). New York, NY: Free 
Press.

Schegloff, E. A. (1982). Discourse as an interactional achievement, some uses of 'uh huh' and other things that come between sentences. In D. Tannen (Ed.), Analysing discourse: Text and talk (pp. 71-93). Washington, DC: Georgetown University Press.

Schegloff, E. A. (1986). Routine as achievement. Human Studies, 9, 111-151.

Schegloff, E. A. (1987a). Between macro and micro: Contexts and other connections. In J. Alexander, B. Giesen, R. Munch \& N. Smelser (Eds.), The micro-macro link (pp. 207-234). Berkeley, CA: University of California Press.

Schegloff, E. A. (1987b). Recycled turn beginnings: A precise repair mechanism in conversation's turn-taking organisation. In G. Button and J. R. E. Lee (Eds.), Talk and social organisation (pp. 70-85). Clevedon, England: Multilingual Matters.

Schegloff, E. A. (1992). In another context. In A. Duranti \& C. Goodwin (Eds.), Rethinking context: Language as an interactive phenomenon (pp. 193-227). Cambridge, England: Cambridge University Press.

Schegloff, E. A. (1996a). Confirming allusions: Toward an empirical account of action. American Journal of Sociology, 102, 161-216.

Schegloff, E. A. (1996b). Turn organization: One intersection of grammar and interaction.

In E. Ochs, E. A. Schegloff, \& S. A. Thompson (Eds.), Interaction and grammar (pp. 52-133). Cambridge, England: Cambridge University Press.

Schegloff, E. A. (1997). Practices and actions: Boundary cases of other-initiated repair. Discourse Processes, 23, 499-545.

Schegloff, E. A. (1998a). Body Torque. Social Research, 65, 535-596. 
Schegloff, E. A. (1998b). Reflections on studying prosody in talk-in-interaction. Language and Speech, 41, 235-263.

Schegloff, E. A. (2007). Sequence organization in interaction: A primer in conversation analysis. Cambridge, England: Cambridge University Press.

Schegloff, E. A. (2013). Ten operations in self-initiated, same-turn repair. In J. Sidnell, M. Hayashi, \& G. Raymond (Eds.), Conversational repair and human understanding (pp. 41-70). Cambridge, England: Cambridge University Press.

Schegloff, E. A. (in press). Increments. In J. Robinson (Ed.), Accountability in social interaction (pp. 21). Oxford, England: Oxford University Press.

Schegloff, E. A., Jefferson, G., \& Sacks, H. (1977). The preference for self-correction in the organization of repair in conversation. Language, 53, 361-382.

Schegloff, E. A., \& Sacks, H. (1973). Opening up closings. Semiotica, 7, 289-327.

Sidnell, J. (Ed.). (2009). Conversation analysis: Comparative perspectives. Cambridge, England: Cambridge University Press.

Sidnell, J. (2010). Conversation analysis: An introduction. Oxford, England: WileyBlackwell.

Sidnell, J. (2013). Basic conversation analytic methods. In J. Sidnell and T. Stivers (Eds.), The handbook of conversation analysis (pp. 77-99). Malden, MA: WileyBlackwell.

Stivers, T. (2008). Stance, alignment, and affiliation during storytelling: When nodding is a token of affiliation. Research on Language and Social Interaction, 41, 31-57.

Stivers, T. (2015). Coding social interaction: A heretical approach in conversation analysis? Research on Language and Social Interaction, 48, 1-19. 
Ting-Toomey, S. (1999). Constructive intercultural conflict management. In S. TingToomey (Ed.), Communicating across cultures. (pp. 194-230). New York, NY: The Guilford Press.

Ting-Toomey, S., \& Chung C. L. (2005). What are the major differences in intercultural verbal styles? In Understanding intercultural communication. (pp. 167-195). Los Angels, CA: Roxbury Publishing Company.

Triandis, H. C. (1995). Individualism \& collectivism. Boulder, CO: Westview Press.

Yngve, V. H. (1970). On getting a word in edgewise. In Papers from the sixth regional meeting of the Chicago linguistic society (pp. 567-578). Chicago, IL: Chicago Linguistic Society. 


\section{Appendix A: HSRRC Approval \\ Portland State University HSRRC Memorandum}

To: Anri Zama

From: Todd Bodner, Chair, HSRRC 2012

Date: October 4, 2012

Re: Your HSRRC application titled, "Conversation Analytic Study of Native and Non-

Native English Interaction 2012” (HSRRC Proposal \#122328)

In accordance with your request, the Human Subjects Research Review Committee has reviewed your proposal referenced above for compliance with DHHS policies and regulations covering the protection of human subjects. The committee is satisfied that your provisions for protecting the rights and welfare of all subjects participating in the research are adequate, and your project is approved.

Please note the following requirements:

Changes to Protocol: Any changes in the proposed study, whether to procedures, survey instruments, consent forms or cover letters, must be outlined and submitted to the Chair of the HSRRC immediately. The proposed changes cannot be implemented before they have been reviewed and approved by the Committee.

Continuing Review: This approval will expire 10/02/2013, one year from the approval date. . It is the investigator's responsibility to ensure that a Continuing Review Report (available in RSP) of the status of the project is submitted to the HSRRC approximately two months before the expiration date, and that approval of the study is kept current.

Adverse Reactions: If any adverse reactions occur as a result of this study, you are required to notify the Chair of the HSRRC immediately. If the problem is serious, approval may be withdrawn pending an investigation by the Committee.

Completion of Study: Please notify the Chair of the Human Subjects Research Review Committee (campus mail code ORSP) as soon as your research has been completed. Study records, including protocols and signed consent forms for each participant, must be kept by the investigator in a secure location for three years following completion of the study. 
If you have questions or concerns, please contact the HSRRC in the Office of Research and Strategic Partnerships, Market Center Building, Suite 620, 1600 SW Fourth Ave, Portland OR 97207 (503)725-2243.

cc: 


\section{Appendix B: HSRRC Approval for Continuation of Project}

$\begin{array}{ll}\text { Post Office Box } 751 & \begin{array}{l}503-725-2227 \text { tel } \\ 503-725-8170 \text { fax }\end{array} \\ \text { Portland, Oregon } 97207-0751 & \begin{array}{l}\text { Committee } \\ \text { hsrrc@lists.pdx.edu }\end{array}\end{array}$

Date: September 29,2015

To: Anri Zama

From: Karen Cellarius, HSRRC Chair

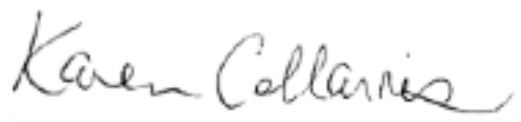

Re: HSRRC approval for continuation of your project titled, "Conversation Analytic Study of Native and NonNative English Interaction 2012"

HSRRC Proposal \# 122328

Approval-Expiration: September 29, 2015 - October 1, 2016

Review Type: Expedited, Category 8 (c)

In accordance with your request, the PSU Human Subjects Research Review Committee has reviewed your request for continuation of the project referenced above for compliance with PSU and DHHS policies and regulations covering the protection of human subjects. The Committee is satisfied that your provisions for protecting the rights and welfare of all subjects participating in the research are adequate, and the continuation of your project is approved. Please note the following requirements:

Approval: You are approved to conduct this rescarch study only during the period of approval cited above; and the research must be conducted according to the plans and protocol submitted (approved copy enclosed).

Consent: Signed consent is no longer required from all participants in this study, as enrollment and data collection are completed.

Changes to Protocol: Any changes in the proposed study, whether to procedures, survey instruments, consent forms or cover letters, must be outlined and submitted to the Committee immediately. The proposed changes cannot be implemented before they have been reviewed and approved by the Committee.

Continuing Review: This approval will expire on 10/01/2016. It is the investigator's responsibility to ensure that a Continuing Review Report on the status of the project is submitted to the HSRRC two months before the expiration date, and that approval of the study is kept current. The Continuing Review Report is available at www.rsp.pdx.edu/compliance human.php and in the Office of Research and Strategic Partnerships (RSP).

Adverse Reactions and/or Unanticipated Problems: If any adverse reactions or unanticipated problems occur as a result of this study, you are required to notify the Committee immediately. If the issue is serious, approval may be withdrawn pending an investigation by the Committee.

Completion of Study: Please notify the Committee as soon as your research has been completed. Study records, including protocols and signed consent forms for each participant, must be kept by the investigator in a secure location for three years following completion of the study (or per any requirements specified by the project's funding agency).

If you have questions or concerns, please contact the Office of Research Integrity in the PSU RSP at 503-725-2227. 


\section{Appendix C: Informed Consent Form for Advisor}

\section{Informed Consent Form \\ Conversation Analytic Study of Native and Non-Native English Interaction}

You are invited to participate in a research project being conducted by Anri Zama from Portland State University, Department of Communication. The researcher hopes to learn about conversation structure between native and non-native speakers of English. This study is being conducted in partial fulfillment of the requirements for a master's degree, and it is under the supervision of Jeffrey D. Robinson, PhD, a Professor of Department of Communication at Portland State University. You were selected as a possible participant in this study because you are native speaker of English and an advisor at the Office of International Affairs, Portland State University.

If you agree to participate, you will be asked to sign this informed consent form and to take a short survey on your background. Your meeting with an international student will be videotaped. Because data may eventually be used to develop training materials, it will be retained for 10 years, stored in the locked office and on the password-protected computer of Dr. Jeffrey Robinson. After 10 years, hard-copy data will be 'shredded' and electronic data will be deleted. To ensure your confidentiality all data and the consent forms will be kept in a separate locked storage cabinet, to which only the researcher has access. Your name and identity will not be used in the work; pseudonyms will be used in all writings, publications or presentations to further protect your confidentiality.

Your participation is completely voluntary. Results from this study about individual advisors and your professional conduct will not be provided to the Office of International Affairs, and thus results will not become the basis for an evaluation of you professionally or personally. You may also refuse videotaping at any time or withdraw from participation completely without penalty. If you chose to stop participation, a remote control unit will be left in the office to use to turn off the recording. Furthermore, you may interrupt to ask questions concerning the research or research procedures at any time.

The study is designed to learn about the experiences and views of people in general and not to benefit you personally.

If you have any questions about this research study, please contact the researcher, Anri Zama at Portland State University, Department of Communication, PO Box 751, 
Portland, Oregon 97207-0751, or (503) 890-0677. If you have concerns or problems about your participation in this study or your rights as a research subject, please contact the Human Subject Research Review Committee, Office of Research and Sponsored Projects, 600 Unitus Bldg., Portland State University, (503) 725-4288 / 1877-480-4400.

Your signature below indicates that you have read and understand the above information and agree to take part in this study. Please understand that you may withdraw your consent at any time without penalty, and that, by signing, you are not waiving any legal claims, rights or remedies. The researcher will provide you with a copy of this form for your own records. Date: 


\section{Appendix D: Informed Consent Form for International Student}

\section{Informed Consent Form \\ Conversation Analytic Study of Native and Non-Native English Interaction}

You are invited to participate in a research project being conducted by Anri Zama from Portland State University, Department of Communication. The researcher hopes to learn about conversation structure between native and non-native speakers of English. This study is being conducted in partial fulfillment of the requirements for a master's degree, and it is under the supervision of Jeffrey D. Robinson, PhD, a Professor of Department of Communication at Portland State University. You were selected as a possible participant in this study because you are an international student at Portland State University.

If you agree to participate, you will be asked to sign this informed consent form and to take a short survey on your background. Your meeting with the advisor will be videotaped. Because data may eventually be used to develop training materials, it will be retained for 10 years, stored in the locked office and on the passwordprotected computer of Dr. Jeffrey Robinson. After 10 years, hard-copy data will be 'shredded' and electronic data will be deleted. To ensure your confidentiality all data and the consent forms will be kept in a separate locked storage cabinet, to which only the researcher has access. Your name and identity will not be used in the work; pseudonyms will be used in all writings, publications or presentations to further protect your confidentiality.

Your participation is completely voluntary. You do not have to take part in this study, and your lack of participation will not affect your course grade or relationship with the Office of International Affairs at Portland State University. You may also refuse videotaping at any time or withdraw from participation completely without penalty. If you chose to stop participation, a remote control unit will be left in the office to use to turn off the recording. The advisors at Office of International Affairs are not conducting this research project, and are not responsible for it; Your lack of participation will not in any way affect the quality of your service. Furthermore, you may interrupt to ask questions concerning the research or research procedures at any time.

The study is designed to learn about the experiences and views of people in general and not to benefit you personally. 
If you have any questions about this research study, please contact the researcher, Anri Zama at Portland State University, Department of Communication, PO Box 751, Portland, Oregon 97207-0751, or (503) 890-0677. If you have concerns or problems about your participation in this study or your rights as a research subject, please contact the Human Subject Research Review Committee, Office of Research and Sponsored Projects, 600 Unitus Bldg., Portland State University, (503) 725-4288 / 1877-480-4400.

Your signature below indicates that you have read and understand the above information and agree to take part in this study. Please understand that you may withdraw your consent at any time without penalty, and that, by signing, you are not waiving any legal claims, rights or remedies. The researcher will provide you with a copy of this form for your own records.

Subject Signature: Date: 
Appendix E: Survey for Advisor

1. What is your birth date? $\frac{\text { Survey }}{/ /}(\mathrm{MM} / \mathrm{DD} / \mathrm{YYYY}) \quad \underline{\text { Advisor\# }}$

2. What is your sex? (Please check the box) $\square$ Male $\square$ Female

\section{Are you of Hispanic, Latino, or Spanish origin?}

$\square$ No, not of Hispanic, Latino, or Spanish origin

$\square$ Yes, Mexican, Mexican American, Chicano

$\square$ Yes, Puerto Rican

$\square$ Yes, Cuban

$\square$ Yes, another Hispanic, Latino, or Spanish origin (specify)

\section{What race do you consider yourself?}

$\square$ White $\square$ Black /African American $\square$ American Indian / Alaska Native

$\square$ Chinese $\square$ Filipino $\square$ Korean $\square$ Japanese $\square$ Vietnamese 
$\square$ Other Asian (please specify)

$\square$ Native Hawaiian/ Other Pacific Islander

$\square$ Other (please specify)

4. What is your native country?

5 . What is your native language?

6. How long have you been advising international students?

Year(s)/ Month(s) 
Appendix F: Survey for International Student

Advisor\# - Student\#

\section{Survey}

1. What is your birth date? (MM/DD/YYYY)

2. What is your sex? (Please check the box) $\square$ Male $\square$ Female

3. Are you of Hispanic, Latino, or Spanish origin?

$\square$ No, not of Hispanic, Latino, or Spanish origin

$\square$ Yes, Mexican, Mexican American, Chicano

$\square$ Yes, Puerto Rican

$\square$ Yes, Cuban

$\square$ Yes, another Hispanic, Latino, or Spanish origin (specify)

\section{What race do you consider yourself?}


$\square$ White $\square$ Black /African American $\square$ American Indian / Alaska Native

$\square$ Chinese $\square$ Filipino $\square$ Korean $\square$ Japanese $\square$ Vietnamese

$\square 0$ ther Asian (please specify)

$\square$ Native Hawaiian/ Other Pacific Islander

$\square 0$ ther (please specify)

4. What is your native country?

5. What is your native language?

6. How long have you been speaking English either in your native country

or in the U.S.? $\quad$ Year(s)/ Month(s)

7. How long have you been living in the U.S.?

Year(s)/ Month(s)

8. What question do you have today?

9. Have you previously visited an advisor at OIA? $\square$ YES $\square$ NO

10. If you answered YES above,

Have you discussed the same question that you are going to talk about today?

$\square$ YES $\square$ NO 